\title{
Neurogenesis in the Caudate Nucleus of the Adult Rabbit
}

\author{
Federico Luzzati, Silvia De Marchis, Aldo Fasolo, and Paolo Peretto \\ Department of Animal and Human Biology, University of Turin, 10123 Turin, Italy
}

\begin{abstract}
Stem cells with the potential to give rise to new neurons reside in different regions of the adult rodents CNS, but in vivo only the hippocampal dentate gyrus and the subventricular zone- olfactory bulb system are neurogenic under physiological condition. Comparative analyses have shown that vast species differences exist in the way the mammalian brain is organized and in its neurogenic capacity. Accordingly, we have demonstrated recently that, in the adult rabbit brain, striking structural plasticity persists in several cortical and subcortical areas. Here, by using markers for immature and mature neuronal and glial cell types, endogenous and exogenously administered cell-proliferation markers, intraventricular cell tracer injections coupled to confocal analysis, three-dimensional reconstructions, and in vitro tissue cultures, we demonstrate the existence of newly formed neurons in the caudate nucleus of normal, untreated, adult rabbit. Our results suggest that neurogenesis in the caudate nucleus is a phenomenon independent from that occurring in the adjacent subventricular zone, mostly attributable to the activity of clusters of proliferating cells located within the parenchyma of this nucleus. These clusters originate chains of neuroblasts that ultimately differentiate into mature neurons, which represent only a small percentage of the total neuronal precursors. These results indicate that striatum of rabbit represents a favorable environment for genesis rather than survival of newly formed neurons.
\end{abstract}

Key words: adult neurogenesis; striatum; local progenitors; calretinin interneurons; neural precursor; caudate nucleus

\section{Introduction}

Several studies have demonstrated that the adult mammalian brain is able to maintain functional neurogenesis (Kempermann et al., 2004a). This is attributable to the persistence of multipotent stem cells (Alvarez-Buylla et al., 2002). In rodents, it has been demonstrated that potential stem cells exist in varying degrees throughout the neuraxis (Reynolds and Weiss, 1992; Kirschenbaum et al., 1994; Weiss et al., 1996; Palmer et al., 1999; Kondo and Raff, 2000), but in vivo only the hippocampal dentate gyrus and the subventricular zone (SVZ) are truly neurogenic during adulthood. Newly formed neurons generated in these areas differentiate into interneurons that can be integrated in the hippocampus and olfactory bulb (OB) circuits (Petreanu and Alvarez-Buylla, 2002; Rochefort et al., 2002; van Praag et al., 2002; Belluzzi et al., 2003; Carleton et al., 2003). In rodents, several experimental paradigms have been demonstrated to induce newly formed neurons in regions that do not normally undergo neurogenesis (Fallon et al., 2000; Magavi et al., 2000; Benraiss et al., 2001; Arvidsson et al., 2002; Chmielnicki et al., 2004). Infusion of growth factors into the lateral ventricles or into adjacent nuclei, coupled or not with lesions such as induction of apoptosis or stroke, determines neurogenesis in the striatum and neocortex. These newly formed neurons originate mainly from the SVZ and differentiate into projection neurons. Locally existing pre-

Received Feb. 11, 2005; revised Nov. 28, 2005; accepted Nov. 29, 2005.

This work was supported by a grant from Compagnia di San Paolo and Fondo per gli Investimenti della Ricerca di Base Grant RBNE01WY7P. We are grateful to Dr. Adam Puche for his precious advice. We also thank Prof. Alessandro Vercelli for the use of Stereo Investigator.

Correspondence should be addressed to Paolo Peretto, Department of Animal and Human Biology, University of Turin, via Accademia Albertina 13, 10123 Turin, Italy. E-mail: paolo.peretto@unito.it.

DOI:10.1523/JNEUROSCI.4371-05.2006

Copyright $\odot 2006$ Society for Neuroscience $\quad$ 0270-6474/06/260609-13\$15.00/0 cursors have also been hypothesized (Magavi et al., 2000). Thus, the SVZ can act, after specific stimuli, as a source of newly formed neurons also for cortical and subcortical areas, opening appealing therapeutic possibilities. More interestingly, recent comparative analyses on mammals suggest that vast species-specific differences may be present in the way the brain is organized and in its neurogenic capacity (Rakic, 2004). Differences, in terms of the organization of adult germinal zones and neurogenesis compared with rodents, have been identified in rabbits (Luzzati et al., 2003) and primates (Gould et al., 1999, 2001; Bernier et al., 2002), including humans (Sanai et al., 2004). In primates, the existence of newly generated neurons in the neocortex, amygdala, and striatum has been described previously (Gould et al., 1999, 2001; Bedard et al., 2002; Bernier et al., 2002). In the adult rabbit brain, we have demonstrated recently the occurrence of chains of newly formed neuroblasts in multiple telencephalic regions (Luzzati et al., 2003). We found that some of these chains originate from extensions of the SVZ and migrate within the mature brain parenchyma toward the frontal cortex and cortical and subcortical areas of the temporal hemisphere. In this work, by using immunocytochemistry for immature and mature neuronal and glial antigens, endogenous and exogenously administered cellproliferation markers coupled to confocal analyses, we demonstrate the occurrence of neurogenesis in the caudate nucleus $(\mathrm{Cd})$ of normal, untreated, adult rabbit brain. Three-dimensional (3D) reconstruction studies, stereotaxic cell tracer injections, and in vitro culture of caudate nucleus tissue explants indicate that neurogenesis in this region is independent from the adjacent SVZ, mostly attributable to the presence of local progenitors able to originate chains of newly formed neuroblasts that ultimately differentiate into mature neurons. 


\section{Materials and Methods}

\section{Animals, 5-bromo-2'-deoxyuridine injections, and} tissue preparation

Experiments were conducted in accordance with current European Union and Italian law, under authorization of the Italian Ministry of Health number 66/99-A. All experiments were designed to minimize the numbers of animals used and their discomfort. Twenty-four sexually mature female (3.5-4 kg body weight; Charles River, Milan, Italy) New Zealand White HY/CR rabbits (Orictolagus cuniculus) were intraperitoneally injected with 5-bromo-2'-deoxyuridine (BrdU; Sigma, Steinheim, Germany) ( $40 \mathrm{mg} / \mathrm{kg}$ body weight in $0.1 \mathrm{M}$ Tris). Seven rabbits were killed $2 \mathrm{~h}$ after a single BrdU injection. Seventeen rabbits received one daily injection of BrdU for 5 consecutive days and were killed $2 \mathrm{~h}(n=5), 10 \mathrm{~d}$ $(n=3), 30 \mathrm{~d}(n=5)$, and $60 \mathrm{~d}(n=4)$ after the last injection. Animals were deeply anesthetized with a ketamine/xylazine solution (100 and 33 $\mathrm{mg} / \mathrm{kg}$ body weight, respectively) and transcardially perfused with icecold saline solution $(0.9 \% \mathrm{NaCl})$, followed by a freshly prepared solution of $4 \%$ paraformaldehyde (PFA) plus $2 \%$ picric acid in $0.1 \mathrm{~m}$ sodium phosphate buffer, $\mathrm{pH}$ 7.4. Brains were then postfixed overnight, cryoprotected, frozen at $-80^{\circ} \mathrm{C}$, and cryostat $(25$ and $40 \mu \mathrm{m})$ sectioned in series.

\section{Stereotaxic cell tracer injections}

A total number of six animals were intramuscularly anesthetized by using a solution of ketamine $(30 \mathrm{mg} / \mathrm{kg})$ and xylazine $(3 \mathrm{mg} / \mathrm{kg})$, and their heads were immobilized on a rabbit stereotaxic apparatus (David Kopf Instruments, Tujunga, CA). The skull was exposed by a skin incision, and small holes were drilled through the skull. One microliter of Cell Tracker Green (CTG) CM-FDA (10 mM in dimethylsulfoxide; Invitrogen, Carlsbad, CA) was bilaterally injected into the lateral ventricles at stereotaxic coordinates of $0 \mathrm{~mm}$ bregma, $2 \mathrm{~mm}$ lateral to sagittal sinus, and $5 \mathrm{~mm}$ depth, by using a glass micropipette and a pneumatic pressure injection apparatus (WPI PV 800; World Precision Instruments, Sarasota, FL). After the injections, the skin was sutured and the animals were left to survive $24 \mathrm{~h}(n=2), 5 \mathrm{~d}(n=2)$, and $9 \mathrm{~d}(n=2)$ before perfusion.

\section{Immunohistochemistry}

Immunohistochemical reactions were performed either by using the biotin-avidin system or double-immunofluorescence methods on sections incubated for $24-48 \mathrm{~h}$ at $4^{\circ} \mathrm{C}$ with the following antibodies: anti-BrdU, 1:2000 (mouse monoclonal; Harlan CPB, Zeist, The Netherlands); antiKi67, 1:300 (MIB1, mouse monoclonal; ScyTek Laboratories, Logan, UT); anti-glial fibrillary acidic protein (GFAP), 1:1000 (rabbit polyclonal; DakoCytomation, Glostrup, Denmark), 1:1000 (mouse monoclonal; Boehringer Mannheim, Mannheim, Germany); anti-vimentin, 1:800 (monoclonal; DakoCytomation); anti-brain lipid binding protein (BLBP), 1:1500 (polyclonal; Todd Anthony, Rockefeller University, New York, NY); anti-class III $\beta$-tubulin, 1:600 (TU-J1, mouse monoclonal and polyclonal; Babco, Richmond, CA); anti-human neuronal protein $\mathrm{HuC} / \mathrm{D}, 1: 200$ (monoclonal; Invitrogen); anti-neuronal-specific nuclear protein (NeuN), 1:1000 (monoclonal; Chemicon, Temecula, CA); antidoublecortin (DCX), 1:500 (goat polyclonal; Santa Cruz Biotechnology, Santa Cruz, CA); anti-polysialylated neural cell adhesion molecule (PSANCAM), 1:4000 (monoclonal IgM; G. Rougon, Marseille, France); antidopamine and cAMP-regulated phosphoprotein (DARPP-32), 1:1000 (monoclonal; BD Transduction Laboratories, Lexington, KY); anticholine acetyltransferase, 1:1000 (goat polyclonal; Chemicon); antiparvalbumin, 1:5000 (monoclonal; Swant, Bellinzona, Switzerland); anti-calretinin, 1:2000 (rabbit polyclonal; Swant); anti-nitric oxide synthase (NOS), 1:200 (rabbit polyclonal; Eurodiagnostica, Stockholm, Sweden); and anti-somatostatin, 1:2000 (a-SRIF, rabbit polyclonal; Dr. R. Benoit, Montreal, Quebec, Canada). All of the antibodies were diluted in a solution of $0.01 \mathrm{M}$ PBS, pH 7.4, containing $0.5-1 \%$ Triton X-100. For BrdU staining, DNA was denatured in $2 \mathrm{~N} \mathrm{HCl}$ for $30 \mathrm{~min}$ at $37^{\circ} \mathrm{C}$. Sections were then rinsed in $0.1 \mathrm{M}$ borate buffer, $\mathrm{pH}$ 8.5. When used in combination with other primary antibodies, sections were processed first for partner antibodies and only afterward for the BrdU reaction. For the biotin-avidin system, sections were rinsed in PBS, incubated with the appropriate biotinylated secondary antibodies for $1 \mathrm{~h}$ ( $1: 250$; Vector Laboratories, Burlingame, $\mathrm{CA}$ ), rinsed, and incubated in avidin-biotin com- plex (1:400; Vector Laboratories). The reaction product was visualized

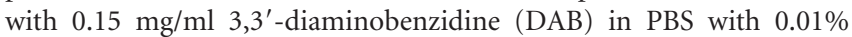
$\mathrm{H}_{2} \mathrm{O}_{2}$. Sections were then serially mounted onto Superfrost Plus slides (Fisher Scientific, Pittsburgh, PA), air dried, dehydrated in graded alcohols, cleared in xylenes, and coverslipped using DPX mounting medium (Aldrich, Milwaukee, WI). For dual immunofluorescence, after incubation with the primary antisera, sections were washed and incubated with appropriate solutions of secondary cyanine 3 (Cy3)-, Cy2-, and Cy5conjugated antibodies (all diluted 1:800, Jackson ImmunoResearch, West Grove, PA). Sections were then coverslipped with anti-fade mounting medium Dabco (Sigma) and analyzed with a laser scanning Olympus Optical (Milan, Italy) Fluoview confocal system (Olympus Optical). All of the antibodies used gave reliable immunoreactions on rabbit tissue. Images were processed by using NIH image J (http://rsb.info.nih.gov/ij/), Adobe Photoshop 7.0 (Adobe Systems, San Jose, CA), and assembled into montages using CorelDraw 11 (Corel, Ottawa, Ontario, Canada). Only general adjustments of color, contrast, and brightness were made. The images were not otherwise manipulated.

\section{Light and confocal $3 D$ reconstructions}

For light 3D reconstructions, three hemispheres from three different animals were serially coronally sectioned ( $40 \mu \mathrm{m}$ thick) and immunolabeled for anti-PSA-NCAM $(n=2)$ and anti-DCX $(n=1)$. Twenty-five consecutive sections at the level of the central part of the body of the caudate nucleus were digitally captured and reciprocally aligned using Reconstruct software version 1.0.2.0 (http://synapses.bu.edu/tools; Copyright 2004, John C. Fiala, Boston University, Boston, MA). For the alignment procedure, we never used the immunostaining as reference to avoid imposing continuity on nonrelated structures. Distortions of images were limited and used only if strictly necessary. Aligned images were imported in Rhino 3D version 3.0 software (Robert McNeel \& Associates, Seattle, WA) and traced. The SVZ-caudate nucleus border was traced on the strength of previous studies (Luzzati et al., 2003) along a line of changing cell density and with the aid of fascicles of fibers that run in the SVZ and avoid striatum (at least the dorsoanterior part of these fibers is referred to as subcallosal bundle) (Romfh, 1976). Inside the caudate nucleus, for all the structures bearing at least three PSA-NCAM/DCXpositive cells with contacting cell bodies, we traced the axis of the chain and constructed around it a pipe whose diameter approximated the diameter of the chain at its end. For confocal 3D reconstructions, two to five consecutive $40-\mu \mathrm{m}$-thick sections were captured with a laser scanning Olympus Optical Fluoview confocal system in stacks of optical images spaced at $1 \mu \mathrm{m}$. Series of sections were entirely acquired, and the stacks were saved as sequences of .tiff images, four-figure numbered, the first figure representing the section number and the others the image number inside the stack. The resulting sequence of images was imported in Reconstruct software for alignment of the different stacks/sections by point correspondence. At least three structures that traversed perpendicularly the limit between two sections were marked by points on the first .tiff image of the following stack and the last .tiff image of the previous stack. The points were aligned using rigid function. Propagate function was used to preserve alignment between images bearing to the same stack. The sequence of images representing the entire aligned volume were mounted on a single stack and observed using NIH image J software.

\section{Tissue explants cultures}

Seven adult rabbits were deeply anesthetized with a ketamine/xylazine solution (100 and $33 \mathrm{mg} / \mathrm{kg}$ body weight, respectively) and killed by rapid decapitation. Three animals received an intraperitoneal injection of 100 $\mathrm{mg} / \mathrm{kg}$ BrdU $3 \mathrm{~h}$ before they were killed.

Brains were dissected out and placed into Petri dishes containing icecold Leibovitz's L-15 medium (Invitrogen). Using a razor blade, the brains were cut in the coronal plane at the level of the optic chiasm and bisected along the midsagittal line. The tissue block was included in 3\% low gelling point agarose (Sigma) and vibratome coronally sectioned at $300 \mu \mathrm{m}$ thick.

Microdissections of SVZ and caudate nucleus were obtained by performing two cuts at, respectively, $\sim 300$ and $600 \mu \mathrm{m}$ lateral from the 
ependymal layer (see Fig. 7C), under a high-magnification dissecting microscope (Leica, Nussloch, Germany). Each tissue section was oriented so that the ventricular surface was completely visible, and the first cut was performed slightly lateral to the SVZ to ensure that the whole SVZ was included in the first stripe. The fourth layer of the parietal cortex was dissected from the same sections. The stripes containing the SVZ and those of purely striatal or cortical tissues were fragmented in small pieces and plated onto $30 \mathrm{~mm}$ Millicell inserts (Millipore, Bedford, MA) coated with a thin layer of Matrigel (BD Biosciences, San Jose, CA). Approximately 20-30 explants of each tissue type were plated in every cell insert and maintained in a humidified incubator $\left(37^{\circ} \mathrm{C}, 5 \% \mathrm{CO}_{2}, 23 \% \mathrm{O}_{2}\right)$. The culture medium consisted of Neurobasal medium (Invitrogen) supplemented with $\mathrm{N} 2$ supplement (Invitrogen), $0.5 \mathrm{~mm}$ glutamine (Invitrogen), and $25 \mu \mathrm{g} / \mathrm{ml}$ gentamycin (Invitrogen). After $4 \mathrm{~d}$ in vitro (div), cultures were fixed $1 \mathrm{~h}$ in 4\% PFA and processed for DCX and BrdU immunohistochemistry as described previously.

\section{Quantifications and statistical analysis}

The number of BrdU cells in the caudate nucleus was counted on a 1-in-12 series of sections ( $25 \mu \mathrm{m}$ thick) covering its entire rostrocaudal extension. Estimates of the total number of BrdU-positive nuclei stained with the peroxidase/DAB method were obtained with the aid of Stereo Investigator (MicroBrightField, Colchester, VT). Sampling of the caudate nucleus was performed by randomly translating a grid with $480 \times$ $300 \mu \mathrm{m}$ squares onto the section of interest and applying a counting frame of $240 \times 150 \mu \mathrm{m}$. The optical fractionator principle (Gundersen et al., 1988; Williams and Rakic, 1988) was modified in that only the labeled cells in the uppermost focal plane (at $40 \times$ ) were excluded to avoid oversampling, as described by others (Kempermann et al., 1997; Kronenberg et al., 2003).

The total number of double-labeled BrdU/DCX- and BrdU/NeuNpositive cells was evaluated using the confocal microscope in a 1-in-12 series of sections ( $25 \mu \mathrm{m}$ thick). Only the labeled cells in the uppermost focal plane (at $100 \times$ ) were excluded to avoid oversampling. Nevertheless, because the double-labeled cells were very rare, the optical fractionator method was further modified in that the double-positive cells were counted exhaustively in the caudate nucleus according to Kempermann et al. (2003). The percentage of double-labeled cells on the entire BrdU population was obtained from the ratio of their estimates. In the same series of sections, we also counted the number of the DCX immunopositive "striatal chain." We considered a chain a group of at least four cells with closely contacting cell bodies.

Phenotypic analyses. The phenotypic analyses of newly generated neurons were performed on six hemispheres of six different animals, which survived $5 \mathrm{~d}(n=3)$ and $65 \mathrm{~d}(n=3)$ from the first of five BrdU injections. The hemispheres were coronally sectioned in 12 series (each $25 \mu \mathrm{m}$ thick) included between the rostral end of the caudate nucleus and the posterior end of the anterior commissure (precommissural caudate nucleus). Each series was double immunolabeled for specific neuronal antigens and BrdU, and the newly generated cells were counted. The volume was evaluated in the first series of sections and assumed as $1 / 12$ of the total volume of the precommissural caudate nucleus.

Density of calretinin cell population. The density per cubic millimeter of the calretinin cell population in this region was estimated from three representative $25-\mu \mathrm{m}$-thick sections per animal $(n=3)$. Sections were stained by using the biotin-avidin system and mounted in Dabco (Sigma) without dehydrating. The percentage of newly generated calretinin cells was obtained by dividing their density by the mean density calculated for the striatal calretinin population.

Nuclei diameters. Nuclei mean diameters were calculated from digital images using Image-pro plus software (Media Cybernetics, Silver Spring, MD).

Striatal chains and Ki67 clusters. The number of striatal chains and Ki67 clusters was counted in two parallel consecutive series of four sections spaced at $300 \mu \mathrm{m}(n=10)$.

Quantification in Ki67 clusters. Quantification of BrdU ( $n=16)$, DCX $(n=3)$, and BLBP $(n=3)$ in the Ki67 clusters was performed in 20 randomly chosen clusters by counting the number of clusters containing at least a single BrdU-, DCX-, or BLBP-positive cell. To establish the percentage of double-immunolabeled cells in the clusters, we calculated the total number of Ki67 cells of the 20 clusters. The occurrence of double immunolabeling was always established with the confocal microscope.

In vitro analysis. The mean number of DCX neuroblasts migrated out of the explants was established in 20 explants per animal $(n=7)$. Percentage of DCX/BrdU-positive cells migrated out of the explants was estimated by collecting the total number of DCX- and DCX/BrdUpositive cells for each explant. Quantification was performed by counting a minimum of $10 \mathrm{DCX} / \mathrm{BrdU}$-positive cells, in at least four explants, for each considered region. Mean values were obtained from three different animals.

Statistical analyses. Statistical analyses were performed by using SPSS 12.0 (SPSS, Chicago, IL). ANOVA was followed by Tukey's post hoc test when appropriate.

\section{Results \\ Newly generated neurons in the caudate nucleus of adult rabbit}

Our recent data suggest the putative existence of neurogenesis in different cortical and subcortical areas of the adult rabbit brain (Luzzati et al., 2003). Here, to establish whether neurogenic events do occur in the corpus striatum of the adult rabbit brain, we performed a confocal analysis on representative sections of the whole region by coupling anti-BrdU and anti-NeuN to identify mature neurons (Mullen et al., 1992) at different survival times after BrdU administration. BrdU was injected intraperitoneally $(40 \mathrm{mg} / \mathrm{kg}$ ) daily for 5 consecutive days, and the animals were allowed to survive $5(n=5), 15(n=3), 35(n=5)$, and 65 $(n=3)$ days from the first injection.

At $5 \mathrm{~d}$ survival time, BrdU was detected in many nuclei scattered throughout the striatum, occasionally organized in clusters. As described previously (Luzzati et al., 2003), a strong BrdU immunoreaction also was found associated with the adjacent SVZ (data not shown). In these animals, no NeuN/BrdU doublelabeled cells were identified in any part of the striatum. In contrast, 35 and $65 \mathrm{~d}$ after BrdU administration, in all of the examined specimens $(n=8)$, double-immunopositive NeuN/BrdU cells were present (Fig. $1 A, B$ ) in the entire rostrocaudal extent of the caudate nucleus, mostly confined to its anterodorsomedial portion. These cells showed strong NeuN immunostaining in the nucleus, cytoplasm of the cell body, and the proximal part of the cell processes. From a morphological point of view, they appeared indistinguishable from the surrounding NeuN-positive BrdU-negative neurons. The nuclei of the NeuN/BrdU-positive cells have a medium to large diameter $(9.97 \pm 1.42 \mu \mathrm{m} ; n=44)$ and contained dispersed clumps of BrdU-positive chromatin. Frequently, a nucleolus was identified (Fig. $1 A, B$ ).

To estimate the time course of the appearance of the newly generated neurons in the caudate nucleus, the total number of BrdU/NeuN-positive cells was stereologically estimated at all survival times (Fig. 1D). Five days after the first BrdU injection, no $\mathrm{BrdU} / \mathrm{NeuN}$ double-labeled cells were identified. Only one double-stained cell showing a light NeuN reaction confined to the nucleus was detected at $15 \mathrm{~d}$ survival. In contrast, in the long-term survivors, the number of the newly generated NeuNpositive cells significantly increased ( 5 vs $35, p=0.001 ; 5$ vs 65 , $p=0.002)$. No statistically significant differences were found in the number of newly generated neurons between 35 and $65 \mathrm{~d}$ $(p=0.954)$ (Fig. 1D). In these animals $(n=8)$, the number of newly generated neurons ranged from 80 to 276 cells (mean \pm $\mathrm{SD}, 172 \pm 67$ cells), indicating a low number and high interindividual variability (Fig. $1 D$ ). The $86 \pm 11 \%$ of newly generated neurons were distributed in the precommissural caudate nucleus. 

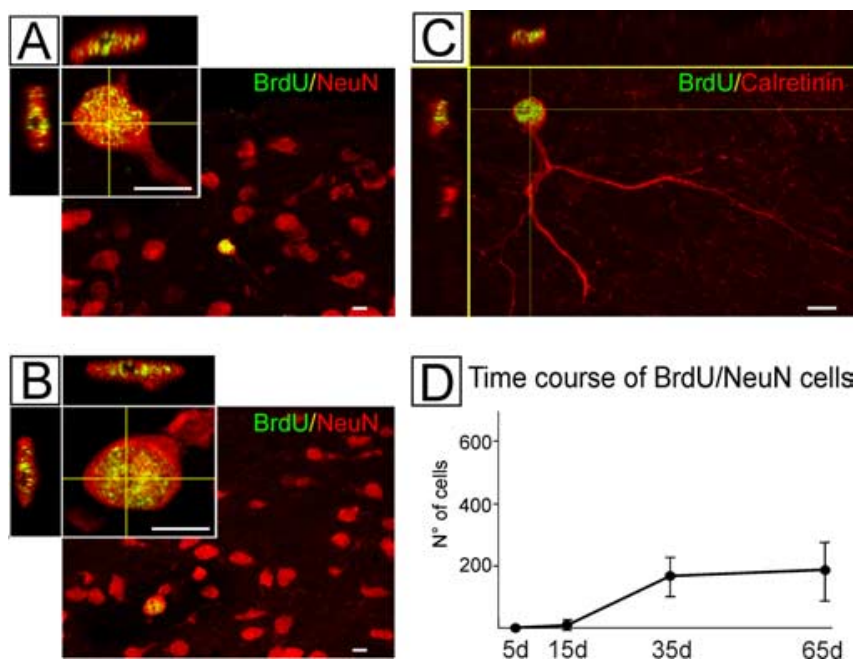

Figure 1. Newly generated neurons in the adult rabbit caudate nucleus. $\boldsymbol{A}-\boldsymbol{C}$, Confocal analysis in the caudate nucleus of adult animals at $65 \mathrm{~d}$ from the first BrdU injection. $\boldsymbol{A}, \boldsymbol{B}$, NeuN/BrdU double-labeled cells from two different animals. Top left, Higher magnifications with reconstructed orthogonal images passing through the nucleolus. The reslicing plane is marked in yellow. $Z$-axis scaling has been compressed. Note the long cell process of the neuron in $\boldsymbol{A}$ and the presence in both neurons of a well evidenced nucleolus; section thickness, $25 \mu \mathrm{m}$. C, Calretinin/ BrdU double-labeled cells. Note the elaborated processes arbor; section thickness, $40 \mu \mathrm{m}$. D Time course of BrdU/NeuN cells. The total number of newly generated neurons is plotted as a function of time from the first BrdU injection ( 5 and $35 \mathrm{~d}, n=5 ; 15$ and $65 \mathrm{~d}, n=3$ ). Values indicate mean \pm SD. Scale bars, $10 \mu \mathrm{m}$.

\section{Newly generated cells of the caudate nucleus can differentiate into calretinin-positive interneurons}

As shown in the previous paragraph, 35 and $65 \mathrm{~d}$ after BrdU administration, it is possible to identify newly generated neurons in the caudate nucleus of the adult rabbit brain. This is consistent with a physiological neurogenic activity in this nucleus. Because NeuN protein shows only the cell body morphology and specific neuronal cell types could not be reliably assigned on the basis of NeuN staining alone, we performed a confocal analysis by coupling the presence of BrdU with markers of the five major classes of striatal neurons (Anderson and Reiner, 1991; Kawaguchi et al., 1995; Rymar et al., 2004). Parallel serial coronal sections (25 $\mu \mathrm{m}$ thick) representative of the entire precommissural caudate nucleus, obtained from three hemispheres of three different animals at $65 \mathrm{~d}$ survival time, were immunolabeled for BrdU, a marker of the spiny projection neurons (DARPP-32), and markers of the striatal interneurons (choline acetyltransferase, parvalbumin, calretinin, NOS, and somatostatin). One series for each animal was stained with anti-NeuN and anti-BrdU and used as reference of the total newly generated neuronal population (Table 1). All of the antibodies used gave reliable immunoreactions in our specimens (data not shown). At 65 d survival time, among all cellspecific markers tested, only calretinin was found associated with the BrdU-positive cells. The density of the BrdU/calretinin double-labeled cells is $0.92 \pm 0.80$ cells $/ \mathrm{mm}^{3}$ and corresponds to nearly one-sixth of the density of the NeuN/BrdU cells (Table 1). Double-labeling experiments confirmed that, in the adult rabbit striatum, calretinin is expressed in a subpopulation of NeuNpositive mature neurons (data not shown). From a morphological point of view, the neo-generated calretinin cells showed features of mature interneurons with elaborate process arbors (Fig. $1 C)$ and are indistinguishable from other surrounding calretinin neurons. Their nucleus dimension was $9.22 \pm 1.34 \mu \mathrm{m}(n=12$ cells from 6 different hemispheres), a value not significantly dif- ferent from that of the NeuN/BrdU cells $(p=0.632)$. Moreover at shorter survival times ( $5 \mathrm{~d} ; n=3$ ) we never found calretinin immunoreactivity associated to the proliferation marker BrdU, further confirming that the expression of this protein in the caudate nucleus is confined to mature neurons. Comparing the density values of the newly generated calretinin cells versus the entire striatal calretinin population, evaluated at the same anteroposterior level in three animals, we found that the newly generated calretinin cells represent $0.1 \pm 0.09 \%$ of the total calretinin striatal interneurons, which corresponds to $901.5 \pm 74.7 \mathrm{cells} / \mathrm{mm}^{3}$. Following these considerations, we can argue that at least part of adult neurogenic activity of the caudate nucleus is devoted to replacing and/or adding calretinin striatal interneurons.

\section{Neuronal precursors are scattered throughout the caudate nucleus}

To unravel the origin of the newly generated neurons of the caudate nucleus, we studied the putative expression in this region of the main neuronal precursor markers described in the adult neurogenic areas (hippocampus and SVZ-OB), namely PSA-NCAM (Bonfanti and Theodosis, 1994), the microtubule binding protein DCX (Brown et al., 2003), and the early neuronal markers class III $\beta$-tubulin (Menezes and Luskin, 1994) and HuC/D protein (Goldman, 1997).

Single labeling and confocal analysis performed on sections treated with combinations of antibodies directed to the above molecules revealed that the caudate nucleus of adult rabbits contains a population of cells positive for all of these markers. PSANCAM and DCX showed a restricted and nearly identical distribution (Fig. 2A), whereas, although fully overlapped with the PSA-NCAM/DCX-positive cells, $\beta$-tubulin and $\mathrm{HuC/D}$ immunolabeling were more widespread (Fig. $2 B, C$ ). In particular, anti$\beta$-tubulin antibody stained virtually all of the neuronal cell bodies as well as many axon bundles (data not shown). Therefore, we focused on the PSA-NCAM/DCX immunostaining.

Cells positive for these molecules were present along the entire rostrocaudal axis of the caudate nucleus mostly confined to its medial and dorsal parts (Figs. 2A, 4A). These cells were either individual or associated as numerous longitudinally arranged cell bodies and processes, which give rise to compact tubular structures that we will refer to as striatal chains (Fig. 2A-C). Often, long and ramified PSA-NCAM/DCX-immunopositive cell processes were observed radiating from the striatal chains in several directions (Fig. 2A). Detailed analyses and $3 \mathrm{D}$ reconstruction studies showed that these cell processes belong to both cells of the striatal chains and individual cells contacting the chains. Individual PSA-NCAM/DCX-positive cells appeared scattered within the nucleus and displayed elongated cell bodies and branched neuritic processes often contacting the chains (Fig. 2A,H-L). Very few bipolar cells were identified (data not shown). As described previously (Luzzati et al., 2003), strong immunolabeling for the same markers was found in the SVZ (Fig. 2A). The number of chains (a group of at least four cells with closely contacting cell bodies), counted on a 1 -in-12 series of sections representative of the whole caudate nucleus, ranged from 84 to 348 (mean \pm SD, $160 \pm 82$ chains; $n=8$ ), indicating strong interindividual variability.

\section{Developmental progression of neuronal precursors from striatal chains to mature neurons}

Expression of the neural precursor markers PSA-NCAM and DCX do not reliably indicate the age of a cell because these molecules are not exclusively associated with newborn/young cells 
Table 1. Phenotypic analysis of newly generated neurons in the precommissural caudate nucleus of three different animals $(A, B, C)$ that survived $65 \mathrm{~d}$ from the first BrdU injection

\begin{tabular}{llllr}
\hline & $65 \mathrm{~d} \mathrm{~A}$ & $65 \mathrm{~d} \mathrm{~B}$ & $65 \mathrm{~d} C$ & Mean \pm SD \\
\hline Number of sections & 16 & 14 & 15 & $15 \pm 1$ \\
NeuN/BrdU cells & 13 & 11 & 6 & $10.00 \pm 3.61$ \\
Calretinin/BrdU cells & 3 & 2 & 0 & $1.67 \pm 1.53$ \\
Density of NeuN/BrdU cells per mm & & 7.02 & 3.52 & $5.67 \pm 1.88$ \\
Density of calretinin/BrdU cells per mm mm $^{3}$ & 1.49 & 1.28 & 0 & $0.92 \pm 0.80$ \\
$\%$ of calretinin/BrdU on NeuN/BrdU cells & 23.08 & 18.18 & 0 & $13.75 \pm 12.16$ \\
\% of calretinin/BrdU on calretinin cells & 0.17 & 0.14 & 0 & $0.10 \pm 0.09$ \\
\hline
\end{tabular}

The study was performed on a representative number of sections of the precommissural caudate nucleus (for details, see Materials and Methods).
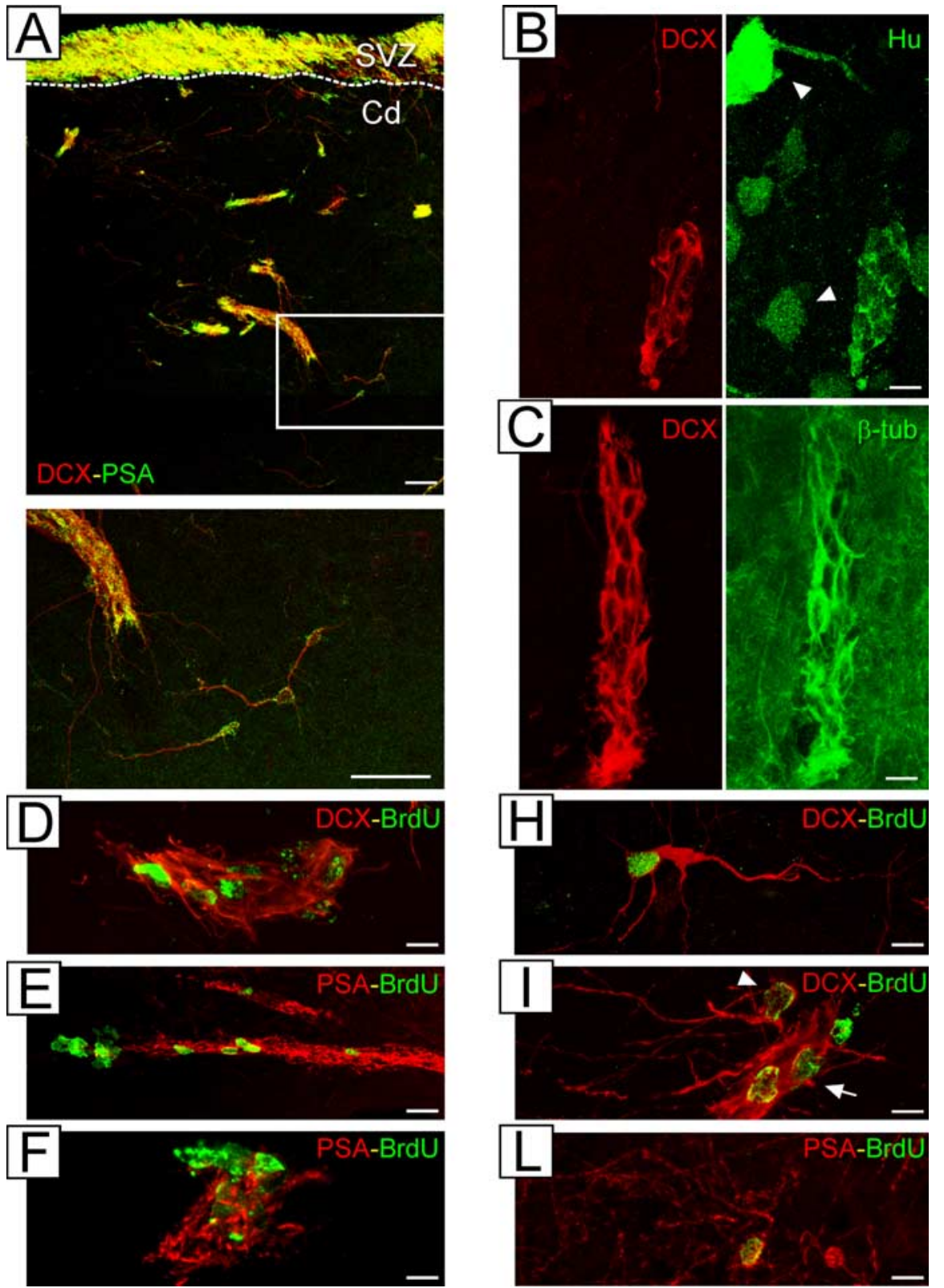

Figure 2. Neuronal precursors in the adult rabbit caudate nucleus. Immunostaining for PSA-NCAM $(\boldsymbol{A}), \operatorname{HuC} / D(B), \beta$-tubulin $(C)$, and $D C X(A-C)$ shows the presence of chains and individual $(A)$ neuronal precursors in the caudate nucleus of adult rabbit. Double labeling indicates high level of coexpression between DCX and PSA-NCAM, whereas $\beta$-tubulin and HuC/D appeared also associated to mature neurons (i.e., white arrowheads in $\boldsymbol{B})$. $\boldsymbol{D}-\boldsymbol{I}$, Both chains $(\boldsymbol{D}-\boldsymbol{F})$ and individual neuronal precursors $(\mathbf{G}-\boldsymbol{I})$ contain BrdU at different survival times after five daily injections ( $5 \mathrm{~d}, \boldsymbol{E}, \boldsymbol{F} ; 15 \mathrm{~d}, \boldsymbol{D} ; 35 \mathrm{~d}, \boldsymbol{G}-\boldsymbol{I})$. In $\boldsymbol{I}$, a DCX/BrdU-positive individual cell (arrowhead) contacts a striatal chain containing newly generated elements (arrow). Note that individual cells show branched neuritic processes. Sections thickness, $25 \mu \mathrm{m}$. Scale bars: $\boldsymbol{A}, 40 \mu \mathrm{m} ; \boldsymbol{E}, 20 \mu \mathrm{m} ; \boldsymbol{B}-\boldsymbol{D}, \boldsymbol{F}-\boldsymbol{I}, 10 \mu \mathrm{m}$.
(Bonfanti et al., 1992; Nacher et al., 2001). Thus, to investigate whether both the striatal chains and individual PSA-NCAM/ DCX-positive cells are newly generated, we performed a BrdU time course analysis in the caudate nucleus. The use of a designbased stereological method allowed us to estimate the numerical dimension of the total BrdU and DCX/BrdU cell populations, their relationships, and the developmental progression of the DCX newly generated cells (Fig. 3).

The absolute number of the BrdUpositive cells within the caudate nucleus was highly variable between animals and did not statistically change at all of the survival times considered, being $44528 \pm$ $38838,32320 \pm 15326$, and $25856 \pm 11652$ cells at $5(n=3), 35(n=3)$, and $65(n=3)$ days, respectively ( $p=0.67)$. In contrast, the number of DCX/BrdU-positive cells decreased $\sim 96 \%$ between 5 and $65 \mathrm{~d}$, passing from $3252 \pm 1878$ to $132 \pm 34$ cells ( $p=0.014$ ) (Fig. $3 B$ ). This reduction became significant at $35 \mathrm{~d}(5$ vs $35 \mathrm{~d}, p=$ $0.05)$, when the DCX/BrdU population had diminished $\sim 72 \%$ ( 5 and $35 \mathrm{~d}, n=5$; 15 and $65 \mathrm{~d}, n=3$ ).

The DCX/BrdU-positive cells represented only $9.1 \pm 2.4,4.3 \pm 3.3$, and $0.4 \pm$ $0.12 \%$ of the total BrdU population at 5 , 35 , and $65 \mathrm{~d}$, respectively (Fig. $3 A$ ).

When we considered the distribution of the DCX/BrdU cells in the striatal neuronal precursor population at 5 and $15 \mathrm{~d}$ survival times, we found that $97.4 \pm 3.4$ and $84.6 \pm 4.6 \%$, respectively, of the double-labeled cells were located in the striatal chains and in smaller groups (two to three cells) of DCX-positive elements. At the same survival times, only $1.7 \pm$ $1.3 \%(5 \mathrm{~d})$ and $15.3 \pm 4.7 \%(15 \mathrm{~d})$ of DCX/BrdU cells were represented by individual elements (Fig. 3C). The percentage of BrdU-positive nuclei in this latter population significantly increased between 15 and $35 \mathrm{~d}(p=0.0001)$ and reached values corresponding to $79.4 \pm 10.1 \%$ of the total DCX/BrdU population at $65 \mathrm{~d}$ (Fig. 3C). These data suggest a temporal redistribution of the BrdU-positive nuclei from striatal chains to individual cells.

Indeed, the analysis of the absolute number of the DCX/BrdU-positive cells in the striatal chains showed a strong decrease between 5 and $65 \mathrm{~d}$, passing from $2870 \pm 1770$ to $28 \pm 27$ ( $p=0.006$ ) (Fig. $3 D)$. In contrast, the number of DCX/ BrdU individual cells (Fig. $3 F$ ) increased between 5 and $35 \mathrm{~d}$ from $54 \pm 41$ to $441 \pm$ 108 cells ( 5 vs $35 \mathrm{~d}, p=0.0003$ ). However, this increase is transient because the number of DCX/BrdU individual cells signifi- 

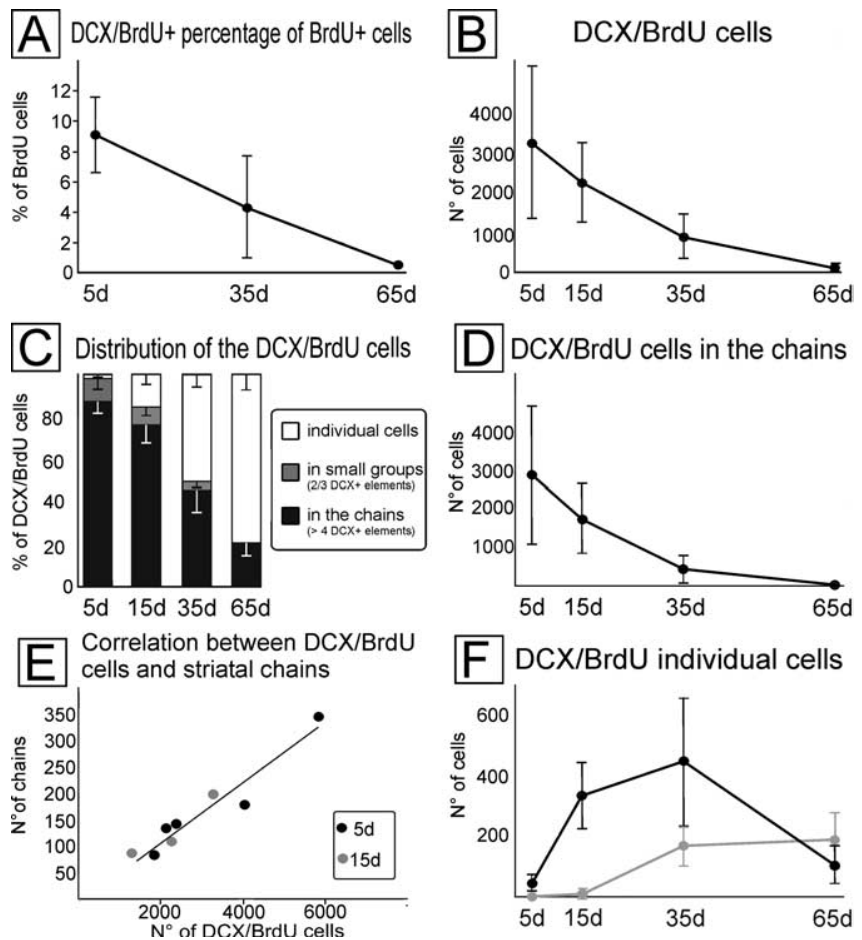

Figure 3. BrdU time course analysis in the caudate nucleus of neuronal precursor cells. $\boldsymbol{A}$ Percentage of DCX/BrdU-positive cells over the total BrdU cell population is plotted as a function of time from the first BrdU injection (5, 35, and $65 d, n=3)$. $B$, Time course analysis of the $\mathrm{DCX} / \mathrm{BrdU}$ cell population ( 5 and $35 \mathrm{~d}, n=5 ; 15$ and $65 \mathrm{~d}, n=3$ ). Note the strong reduction from 5 to $65 \mathrm{~d}$ ( 5 vs $35 \mathrm{~d}, p=0.05 ; 5$ vs $65 \mathrm{~d}, p=0.014$ ). C, Percentage of the BrdU-positive nuclei within DCX individual cells (white), small groups of two to three DCX-positive cells (gray), and striatal chains (black) at different survival times. $D$, Time course analysis of the DCX/BrdU cells in the striatal chains ( 5 vs $35 \mathrm{~d}, p=0.012 ; 5$ vs $65 \mathrm{~d}, p=0.006$ ). $\boldsymbol{E}$, Relationship between the number of $D C X / B r d U$-positive cells and striatal chains counted on the same sections at $5 d$ (black dots) and $15 \mathrm{~d}$ (gray dots). Each animal is plotted individually. Note the great interindividual variability of both variables and the high degree of correlation (correlation coefficient, $0.96 ; n=8)$. $\boldsymbol{F}$, Time course of individual DCX/BrdU cells (dark line). Newly generated cells appear between 5 and $15 \mathrm{~d}$ but are not long lasting because they are strongly reduced after $65 \mathrm{~d}$ ( 5 vs $15 d, p=0.026 ; 5$ vs $35 d, p=0.0003 ; 35$ vs $65 d, p=0.003$ ). Comparison with NeuN/BrdU time course (gray line) indicates comparable number of newly generated cells and a great interindividual variability. Values indicate mean \pm SD.

cantly dropped to $104 \pm 61.6$ cells at $65 \mathrm{~d}$ ( 35 vs $65 \mathrm{~d}, p=0.003$ ). A comparison with the NeuN/BrdU time course (Fig. $3 F$, gray line) indicates that the DCX individual cells arise before the appearance of NeuN newly generated neurons and shows comparable number and interindividual variability, suggesting that the DCX individual cells differentiate into NeuN mature neurons. This developmental progression is further supported by the increase of the mean nuclear diameter observed in newly generated individual cells (PSA-NCAM positive) between $15 \mathrm{~d}(6.13 \pm 1.22$ $\mathrm{mm} ; n=14$ cells $)$ and $35 \mathrm{~d}(7.7 \pm 1.93 \mathrm{~mm} ; n=40$ cells; $p=$ $0.017)$ and between the latter and the BrdU/NeuN-positive cells $(p<0.0001)$.

It has to be remarked that the number of newly generated neuronal precursors is greatly variable among different animals. This variability is particularly high, in absolute numbers, at 5 and 15 d survival times, ranging from 1296 to 5856 cells (mean \pm SD, $2884 \pm 1468$ cells; 5 vs $15 \mathrm{~d}, p=0.66 ; n=8)$. Nevertheless, in these animals, the number of DCX/BrdU cells shows a good correlation with the number of striatal chains, counted on the same sections (Fig. 3E) (correlation coefficient of 0.96; $n=8$ ). These data indicate that, in the adult rabbit caudate nucleus, the occur- rence of chains is strictly correlated with the production of neuronal precursors.

These overall data support a neurogenic model in which, as in the SVZ-OB system, newly generated cells are first organized in chains and then as individual cells that ultimately differentiate into mature neurons. Notably, a strong selection of the newly generated striatal neuroblasts occurs. Indeed, the DCX/BrdU individual cells at $35 \mathrm{~d}$ and the mature neurons at $65 \mathrm{~d}$ represent only $\sim 13$ and $5 \%$, respectively, of the initial BrdU-positive neuronal progenitor population.

\section{Striatal and SVZ chains represent separate populations}

$3 D$ analysis of the striatal chains and their relationships with the $S V Z$

Chains of neuroblasts are characteristic of the SVZ in which they support cell migration to the OB. Recent works indicated the SVZ as source of newly formed cells also for cortical and subcortical areas (Gould et al., 2001; Bernier et al., 2002; Luzzati et al., 2003; Dayer et al., 2005). Thus, to better understand the distribution and orientation of the striatal chains and their relationships with the adjacent SVZ, we performed a $3 \mathrm{D}$ reconstruction of the PSANCAM/DCX-positive chains contained in 25 coronal consecutive sections (each $40 \mu \mathrm{m}$ thick) of the central part of the body of the caudate nucleus (Fig. 4). This study, performed on three animals, confirmed that the striatal chains are mostly confined dorsomedially in the caudate nucleus. The rendered image shows a considerable system of chains with great variability for length and diameter. Anastomoses between the chains also were found (Fig. $4 A-C)$. Although SVZ and striatal chains share common morfoanatomical features, the $3 \mathrm{D}$ analysis showed considerable differences in their spatial arrangement. In particular, SVZ chains, as in rodents (Doetsch and Alvarez-Buylla, 1996), are oriented along the longitudinal axis (data not shown; for a schematic view, see Luzzati et al., 2003), whereas striatal chains show more convoluted paths. Surprisingly, whereas the striatal chains were abundant in the most dorsal part of the striatum, none of them contacted the SVZ and its neuroblasts. Therefore, the 3D analysis showed the existence of a large system of chains in the caudate nucleus of adult rabbit and suggests that striatal and SVZ chains represent two separate populations.

\section{Stereotaxic tracer injections}

By using stereotaxic injections of CTG into the lateral ventricles, we further investigated the relationship between striatal and SVZ chains. In particular, we tried to understand whether the striatal chains could represent ectopic SVZ chains that had migrated out of this germinative area. The compatibility of CTG with immunohistochemistry and its profitable use to investigate SVZ neuroblast migration and differentiation has been shown recently (De Marchis et al., 2001, 2004). Animals were analyzed after different survival times ( $24 \mathrm{~h}, 5 \mathrm{~d}$, and $9 \mathrm{~d}$ ) from the CTG injections. At all the survival times, the CTG intraventricular injections gave a strong ependymal staining (Fig. 5D, $H, I$ ) throughout the ventricular system from the caudal part of the olfactory ventricle to the central canal of the spinal cord (data not shown). An intense staining was also associated to astroglial-like, DCX-negative cells surrounding the whole lateral ventricles (Fig. $5 H, I$ ). Some of these cells were located outside the SVZ.

At $24 \mathrm{~h}$ from CTG injection $(n=2)$, confocal analyses with DCX showed that most of the SVZ neuroblasts at the level of the lateral ventricle were CTG positive (Fig. $5 A-D$ ). No CTG/DCXpositive chains were found along the SVZ rostral extension (RE) or in the surrounding mature brain parenchyma, including the 

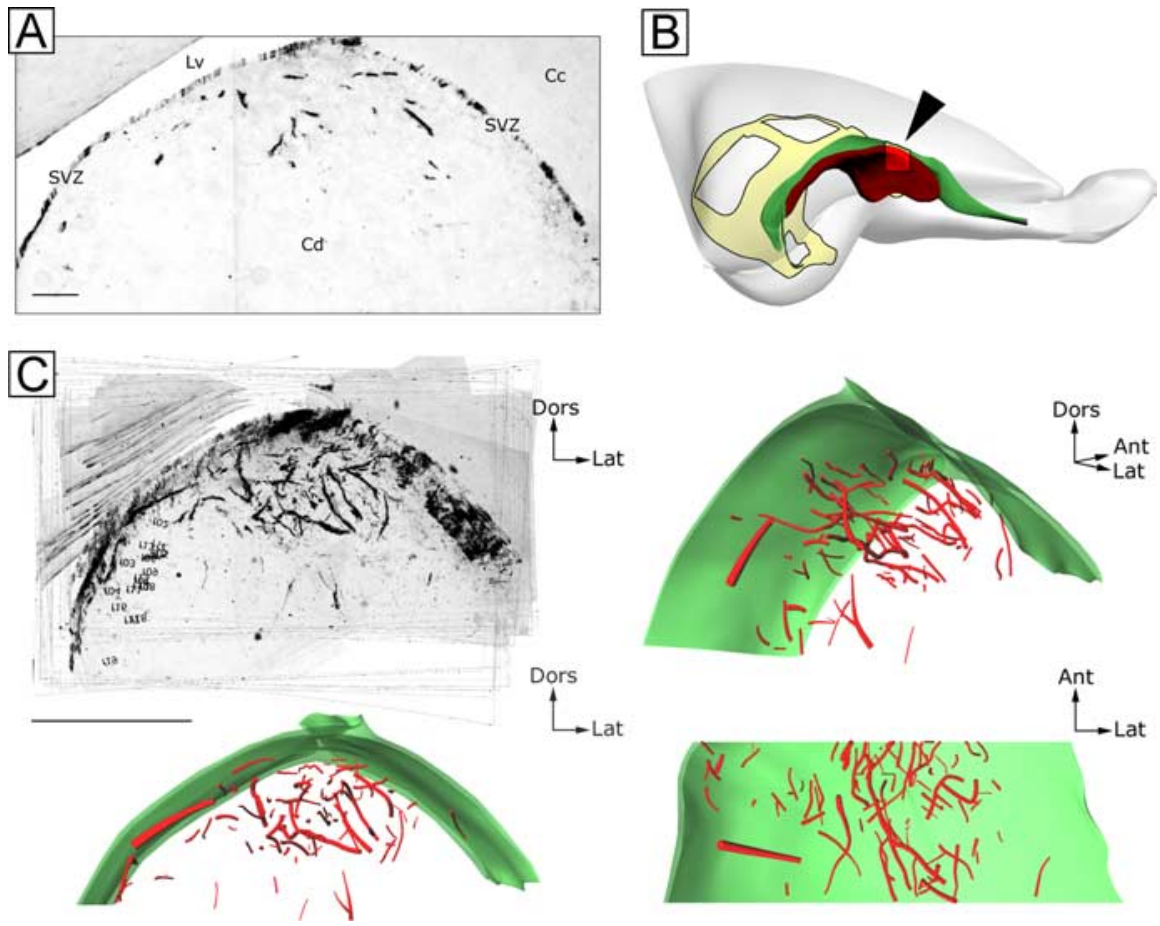

Figure 4. 3D reconstruction of the striatal chains in $1 \mathrm{~mm}$ tract ( 25 consecutive coronal sections) of the dorsal part of the caudate nucleus. $\boldsymbol{A}$, PSA-NCAM labeling in a single representative $40-\mu \mathrm{m}$-thick section. Several immunopositive chains are visible within the SVZ and the caudate nucleus. $\boldsymbol{B}$, Schematic drawing of the adult rabbit brain (lateral view) showing the position of the reconstructed volume (black arrowhead) and adjacent regions (SVZ, green; caudate nucleus, red; lateral ventricle, yellow). C, Top left, Composite image showing all of the sections used for the analysis. Other images are rendered views of the 3D model: bottom left, caudal view; top right, perspective view; bottom right, ventral view. None of the PSA-NCAM-positive chains (red) contacted the SVZ (green). Cc, Corpus callosum; Lv, lateral ventricle; Ant, anterior; Dors, dorsal; Lat, lateral. Scale bars: $\boldsymbol{A}, 200 \mu \mathrm{m} ; \boldsymbol{C}, 1 \mathrm{~mm}$.

nucleus caudate (Fig. 5A-E). At $5 \mathrm{~d}$ from CTG treatment (Fig. $5 F-I$ ), the chains of CTG/DCX-positive neuroblasts were also found in the SVZ rostral extension, thus indicating that SVZ neuroblasts migrated toward the OB (data not shown). Notably at this survival time, chains of CTG/DCX-positive neuroblasts were also identified in the anterior forceps of the corpus callosum (Fig. $5 F, G$ ). These chains, as demonstrated previously by using $3 \mathrm{D}$ reconstruction analysis in the adult rabbit (Luzzati et al., 2003), originate from the SVZ and migrate several micrometers toward the frontal cortex. At $9 \mathrm{~d}$ from tracer injections, most of the SVZ CTG-positive chains reached the core of the OB (data not shown). Some positive neuroblasts were still found at the level of the lateral ventricles. An accurate analysis of the striatal chains showed that no CTG neuroblasts were found associated to these chains at any of the survival times considered (Fig. 5). Despite a complete lack of staining in the striatal chains, we occasionally observed a few DCX/CTG-positive individual cells in the most superficial part of the caudate nucleus bordering the SVZ (data not shown). These cells were found at all of the survival times analyzed, and thus, like the CTG-positive astroglial-like cells located outside the SVZ, they can either efficiently incorporate CTG diffused from the ventricles or originate from the SVZ. These overall results further suggest that striatal chains and SVZ chains are distinct populations.

\section{The striatal chains originate from parenchymal progenitors of the caudate nucleus}

Specialized regions of the chains are proliferating

Our 3D reconstruction study and CTG stereotaxic injection experiments would suggest a different origin of SVZ and striatal chains. Moreover, the BrdU time course analysis demonstrated that, at $5 \mathrm{~d}$ survival time, $>97 \%$ of the newly generated neuronal precursors are associated with the striatal chains. These results suggest that striatal chains can originate from parenchymal progenitors located within the caudate nucleus. To evaluate this hypothesis, we studied the expression of the endogenous marker of cell proliferation Ki67. The proliferating cells express this antigen during the $\mathrm{G}_{1}-\mathrm{S}-\mathrm{G}_{2}-\mathrm{M}$ phases of the cell cycle (Scholzen and Gerdes, 2000). Ki67-positive nuclei were detected in scattered isolated cells in the whole caudate nucleus, being particularly abundant in its most dorsomedial portion, in which small clusters of Ki67-positive nuclei were also found (Fig. 6A). We considered (in 25$\mu \mathrm{m}$-thick sections) a cluster one group of at least three closely contacting Ki67positive cells. By examining $320 \mathrm{Ki} 67$ clusters in 16 different animals, we estimated that the mean number of cells per cluster is $4.5 \pm 2$, whereas in some cases, clusters of 16-18 nuclei were found. Double immunostaining for Ki67 and BrdU, 2 h after BrdU injection, confirmed that the Ki67 clusters contain proliferating BrdUpositive nuclei (data not shown). At $5 \mathrm{~d}$ survival time, in $20 \mathrm{Ki} 67$ clusters considered per animal $(n=4), 95.70 \pm 2.94 \%$ contained BrdU, and $85.2 \pm 6.6 \%$ of the cells in the cluster were colabeled for BrdU and Ki67 (Fig. $6 B$ ). Ten days later $(n=3)$, the number of Ki67 clusters containing BrdU significantly dropped (13.33 \pm 12.58 ; $p<0.001$ ), and, at $65 \mathrm{~d}$, we never found any Ki67 cluster containing BrdU-positive nuclei (Fig. 6B). These data indicate that the Ki67 clusters within the caudate nucleus represent local dynamic foci of active proliferation. Moreover, although the Ki67 clusters number is highly variable in different animals, the comparison with the number of PSA-NCAM-positive chains, established in parallel consecutive sections, showed a high correlation between number of clusters and striatal chains (Fig. 6C) (correlation coefficient, 0.92). Confocal analysis for PSA-NCAM or DCX and Ki67, and 3D reconstruction, showed a close relationship between Ki67 clusters and striatal chains (Fig. 6D,E) and revealed coexpression of Ki67 and PSA-NCAM (data not shown) or DCX within the clusters (Fig. 6D,E). In double-labeled Ki67/ DCX cells, DCX immunostaining appeared light but unequivocal (Fig. $6 E$ ). An analysis of 20 clusters per animal ( $n=3$; in $25-\mu \mathrm{m}$ thick sections) indicated that, on average, $76.6 \pm 2.9 \%$ of the Ki67 clusters contained DCX-positive cells and that these cells represented $59.5 \pm 5 \%$ of the total number of cells in the clusters (Fig. 6E, bottom right). Thus, we demonstrate that striatal chains contain actively proliferating regions that represent their most likely site of origin.

\section{Striatal neuronal progenitors are BLBP positive}

Different studies indicate that both during embryogenesis (Anthony et al., 2004) and adulthood (Alvarez-Buylla et al., 2002) glial cells play a key role in neurogenesis, acting as neural progenitor cells. We therefore investigated the expression of glial mark- 

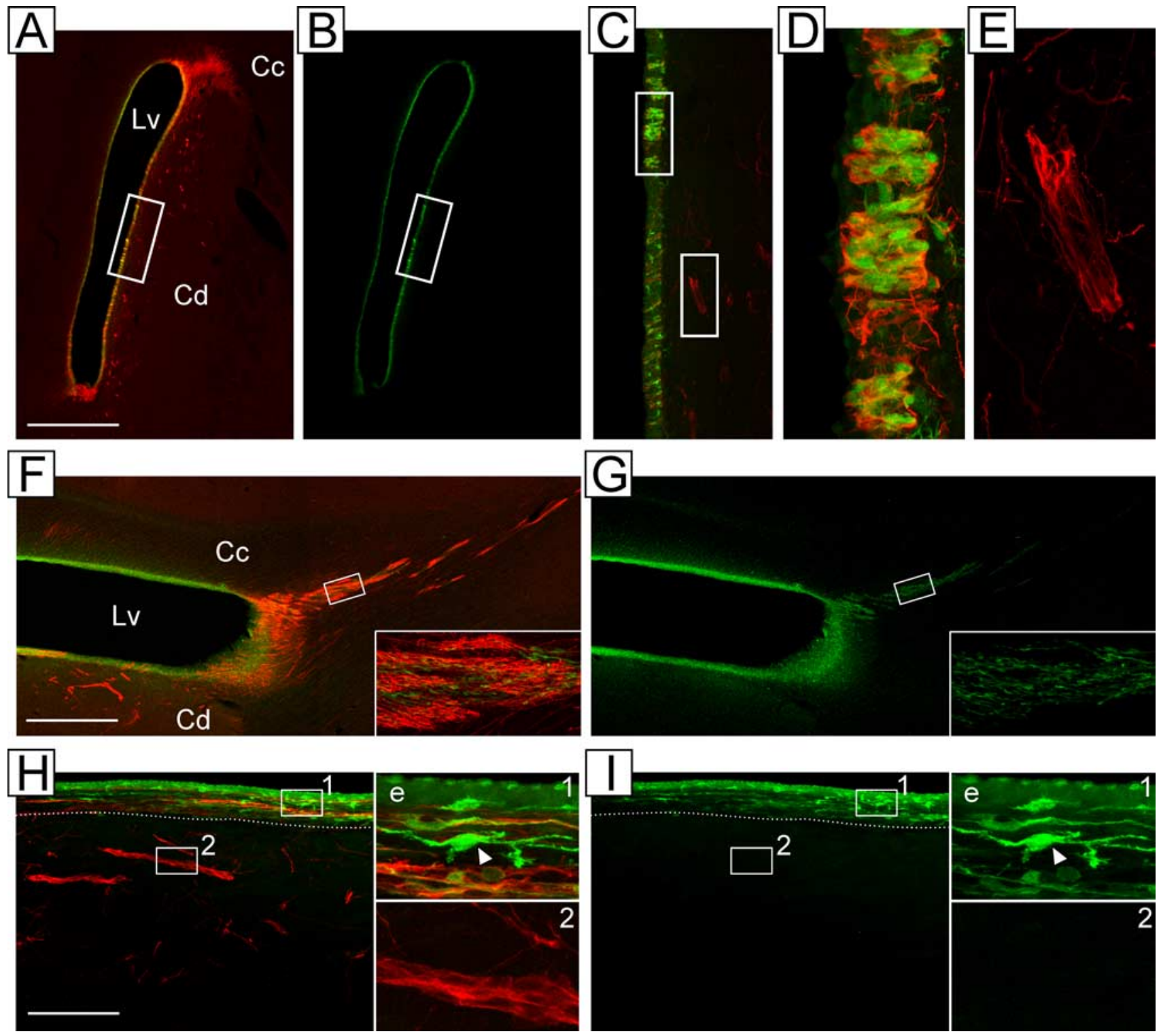

Figure 5. Stereotaxic injections of CTG (green) into the lateral ventricles of the adult rabbit. Anti-DCX (red)-treated sections obtained from animals analyzed $24 \mathrm{~h}$ ( $\boldsymbol{A}-\boldsymbol{E}$, coronal view; top, dorsal; right, medial) and $5 \mathrm{~d}(\boldsymbol{F}-\boldsymbol{I}$, parasagittal view; top, dorsal; left, anterior) after (TG treatment. At $24 \mathrm{~h}$ survival time, a strong (TG staining was found associated to most of the DCX-immunopositive neuroblasts located at the level of the lateral ventricles $(\boldsymbol{A}-\boldsymbol{D})$. At $5 \mathrm{~d}$ survival time, DCX/CTG-positive SVZ neuroblasts migrated several micrometers toward the frontal cortex $(\boldsymbol{F}, \boldsymbol{G})$. At all of the survival times considered, striatal chains never contained CTG staining $(\boldsymbol{C}, \boldsymbol{E}, \boldsymbol{F}-\boldsymbol{I})$. CTG-positive, DCX-negative, glial-like cells were identified in the SVZ (arrowheads in $\boldsymbol{H}$ and $\boldsymbol{I}$ ). The dotted line in $\boldsymbol{H}$ and $\boldsymbol{I}$ represents the SVZ limit. (TG staining was also associated to the ependymal cells (see boxed areas 1 in $\boldsymbol{H}, \boldsymbol{I}$ ). C is a higher magnification of $\boldsymbol{A}$ and $\boldsymbol{B}$, and $\boldsymbol{D}$ and $\boldsymbol{E}$ are higher magnifications of C. CC, Corpus callosum; e, ependymal cells; Lv, lateral ventricle. Scale bars: $\boldsymbol{A}, \boldsymbol{B}, \boldsymbol{F}, \boldsymbol{G}, 0.5 \mathrm{~mm} ; \boldsymbol{C}, \boldsymbol{H}, \boldsymbol{I}$ and insets in $\boldsymbol{F}, \mathbf{G}, 100 \mu \mathrm{m} ; \boldsymbol{D}, \boldsymbol{E}$ and insets in $\boldsymbol{H}, \boldsymbol{I}, 20 \mu \mathrm{m}$.

ers within the caudate nucleus and the relationship of the glial cells with both the proliferating Ki67-positive clusters and the striatal chains. To this end, a confocal analysis was performed by comparing the expression of Ki67 and/or DCX with that of the GFAP, a characteristic molecule expressed by adult astrocytes, and the BLBP. The latter protein has been demonstrated to be specifically associated to the radial glial cells and astrocytes throughout development (Feng et al., 1994; Kurtz et al., 1994; Hartfuss et al., 2001). GFAP expression was found in several cells of the caudate nucleus. Numerous GFAP-positive cell processes were in contact with both striatal chains and Ki67 clusters. Whereas some GFAP-positive astrocytes were found closely associated to the Ki67 clusters, only rarely were GFAP/Ki67 doubleimmunopositive cells identified (data not shown). BLBP immunostaining in the caudate nucleus showed many astroglial-like cells, mostly GFAP positive (data not shown). Cells showing strong BLBP expression in the nucleus, cell body, and processes were found associated to both the Ki67 clusters and striatal chains (Fig. 6F). However, these cells were only rarely Ki67 positive. Conversely, a subpopulation of BLBP-positive cells showing light nuclear staining and cluster arrangement frequently coexpresses Ki67 (Fig. 6F, G). Quantification, performed by examining 20 Ki67-positive clusters per animal $(n=3)$, indicated that $95.5 \%$ of the clusters do contain at least one BLBP-positive cell and that, within each cluster, the BLBP-positive elements represent $86.25 \pm 3 \%$ of the cells (Fig. $6 G$, bottom right). By comparing these values with the percentage of double-immunopositive Ki67/DCX cells (see previous paragraph), we can argue that some Ki67-positive cells express both DCX and BLBP. This was confirmed by triple-labeling experiments (Fig. $7 A, B$ ). Finally, a cer- 

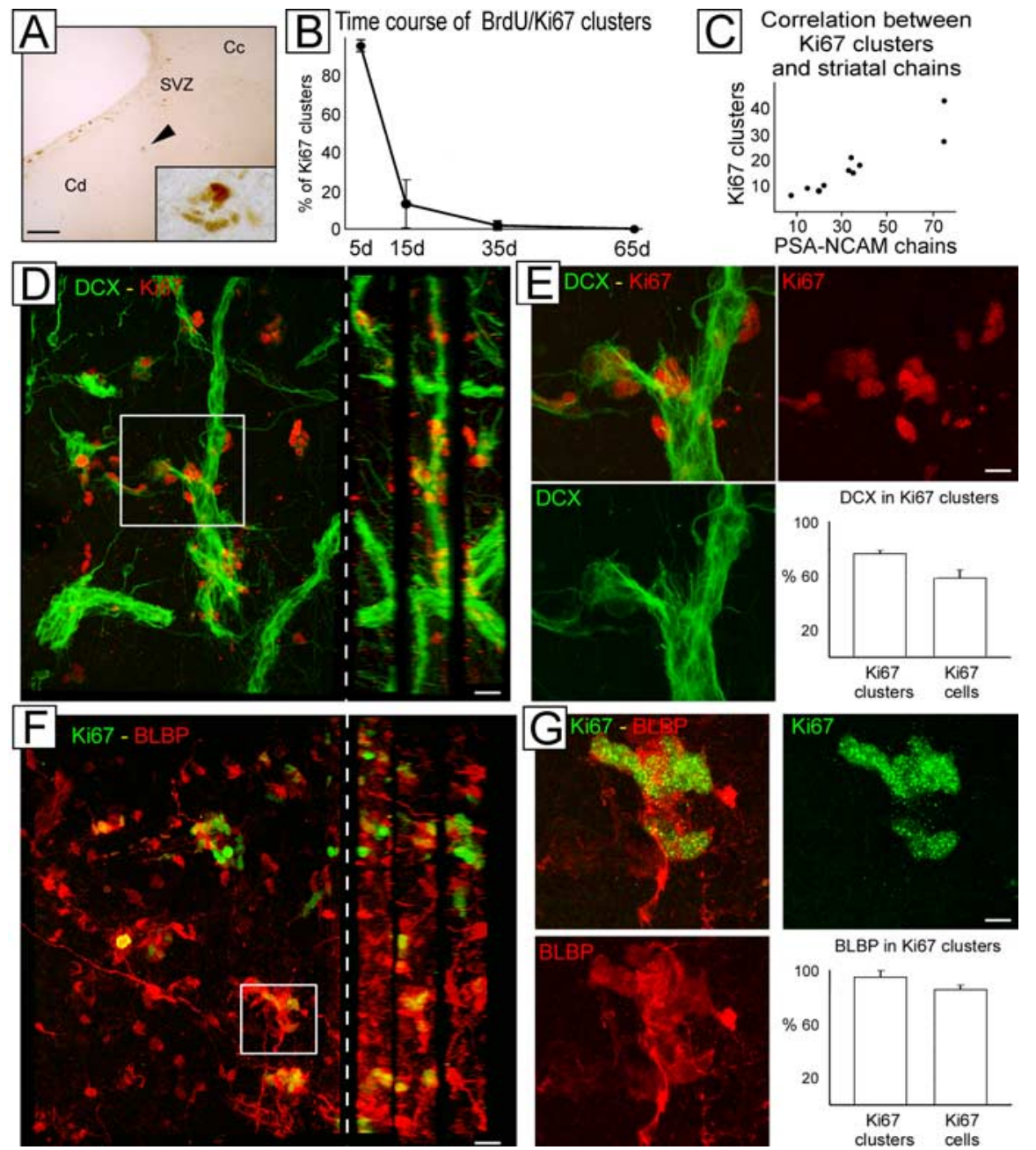

Figure 6. Parenchymal progenitors of the adult caudate nucleus. $A$, Ki67 immunoreactivity in a coronal $25-\mu \mathrm{m}$-thick section including the SVZ and the dorsomedial part of the caudate nucleus. Numerous Ki67-positive nuclei are visible in the SVZ. Small Ki67-positive clusters also are present (black arrowhead) in the $\mathrm{Cd}$. Bottom right, Higher magnification of the Ki67 cluster (the image results from 3 photomicrograph taken at different focal planes). $\boldsymbol{B}$, Time course of BrdU/Ki67-positive clusters. Dark line, The percentage of Ki67 clusters containing at least one BrdU-positive nuclei over 20 sampled Ki67 clusters is plotted as a function of time from the first BrdU injection ( 5 and $35 d, n=5 ; 15$ and $65 d, n=3$ ). Note the quick reduction with time from the last BrdU injection ( 5 vs $15 \mathrm{~d}, p<0.0001$ ). Note the reduction of newly generated cells in the chains starts only when clusters have lost BrdU staining. C, Relationship between the number of Ki67 clusters and PSA-NCAM-positive chains counted on four 25- $\mu \mathrm{m}$-thick sections. Each animal is plotted individually. Note the great interindividual variability of both variables and the high degree of correlation (correlation coefficient, 0.92 ; mean \pm SD chains per cluster, $2.0 \pm 0.5 ; n=10$ ). $\boldsymbol{D}, \boldsymbol{F}$, Confocal reconstruction of three sections (40 $\mu \mathrm{m}$ thick) double immunostained for Ki67 and DCX $(\boldsymbol{D})$ or $\operatorname{BLBP}(\boldsymbol{F})$. The dotted lines separate frontal (left) and lateral (right) views. Dark spaces visible in the lateral view indicate the border of the three reconstructed sections. Note that, in $D$, several Ki67 clusters are closely associated to the striatal chains. $\boldsymbol{E}, \boldsymbol{G}$, Higher magnifications of the boxed areas in $\boldsymbol{D}$ and $\boldsymbol{F}$ showing double-stained Ki67/DCX (E) or Ki67/BLBP (G) cells. Bottom right, Percentage of Ki67 clusters containing at least one DCX-positive $(\boldsymbol{E})$ or BLBP-positive $(\boldsymbol{G})$ cell over 20 sampled Ki67 clusters (Ki67 clusters column), and percentage of double-stained cells within clusters (Ki67 cells column). Values indicate mean \pm SD. Scale bars: $\boldsymbol{A}, 150 \mu \mathrm{m}$; inset in $\boldsymbol{A}, 15 \mu \mathrm{m} ; \boldsymbol{D}, \boldsymbol{F}, 20 \mu \mathrm{m} ; \boldsymbol{E}, \mathbf{G}, 10 \mu \mathrm{m}$.

tain degree of coexpression between BLBP and DCX was also found associated to some nonproliferating cells of the chain system (Fig. 7A, arrow). Note that, in these cells, BLBP immunostaining is light and always excluded from the nucleus. In conclusion, these results indicate that the proliferating progenitor of the striatal chains express markers associated to the radial glial cells and astrocytes.

\section{Locally formed neuronal precursors migrate out from} caudate nucleus tissue explants cultured in vitro

In the previous paragraph, we demonstrated the existence of regions of active proliferation scattered within the caudate nucleus
BLBP in Ki67 clusters

parenchyma and strictly associated with the striatal chains. To further investigate the neurogenic capacity of this region, we cultured in vitro tissue explants dissected from the dorsomedial part of the caudate nucleus. As positive control, we used explants containing the SVZ, obtained at the level of the lateral ventricle $(S V Z+C d)$, and of its RE. Explants of the fourth layer of the parietal cortex were used as negative control. Tissue explants were cultured on a thin layer of matrigel up to $4 \mathrm{~d}$. Three animals received an intraperitoneal BrdU injection $3 \mathrm{~h}$ before suppression (Fig. $7 C-E, G, H)$.

A great number of DCX-positive cells, often organized as chains, were found surrounding all of the SVZ $+\mathrm{Cd}(233.7 \pm 18.7$ cells per explant) (Fig. 7D) and RE explants (360.5 \pm 32.3 cells per explant; 20 sampled explants per experiment; $n=7$; data not shown). In contrast, only a limited number of individual cells (24.2 \pm 22.2 cells per explant) migrated out from $71.1 \pm 23.3 \%$ of the caudate nucleus explants (20 sampled explants per experiment; $n=7$ ) (Fig. 7E). No DCX-positive cells migrated out from control cortical tissue (data not shown).

Double immunostaining between DCX and BrdU showed the occurrence of colabeled cells in the $\mathrm{Cd}, \mathrm{SVZ}+\mathrm{Cd}$, and $\mathrm{RE}$ cultured tissue regions. Notably, the percentage of the BrdU/DCX-positive cells migrated out of the Cd and SVZ+Cd containing explants showed no differences $(p=0.923)$. In contrast, this value was significantly lower in the RE (Cd vs RE, $p=0.009)$, consistent with previous data in vivo showing that the $\mathrm{RE}$ is mainly a region of migration with reduced proliferative activity (Luzzati et al., 2003). Thus, although the number of migrating neuroblasts is clearly lower in the Cd compared with the SVZ $+\mathrm{Cd}$, the fraction of newly generated elements in both of these region is comparable, indicating a relevant $\mathrm{Cd}$ neuronal progenitors activity. These overall results support our in vivo data indicating the existence of proliferative neuroblasts progenitors in the caudate nucleus parenchyma. Interestingly, no clearly definable chains were present in the Cd explants at 4 div. Because the occurrence of these structures was present in vivo and at 0 div (data not shown), we can argue that the DCX isolated elements distributed both inside and outside the Cd explants derive from the dissolution of the chains.

\section{Discussion}

Here we demonstrate the presence of neurogenic activity in the striatum of the adult rabbit under normal conditions. Our in vivo and in vitro data indicate that addition of new neurons in this region is attributable to the proliferative activity of progenitor 

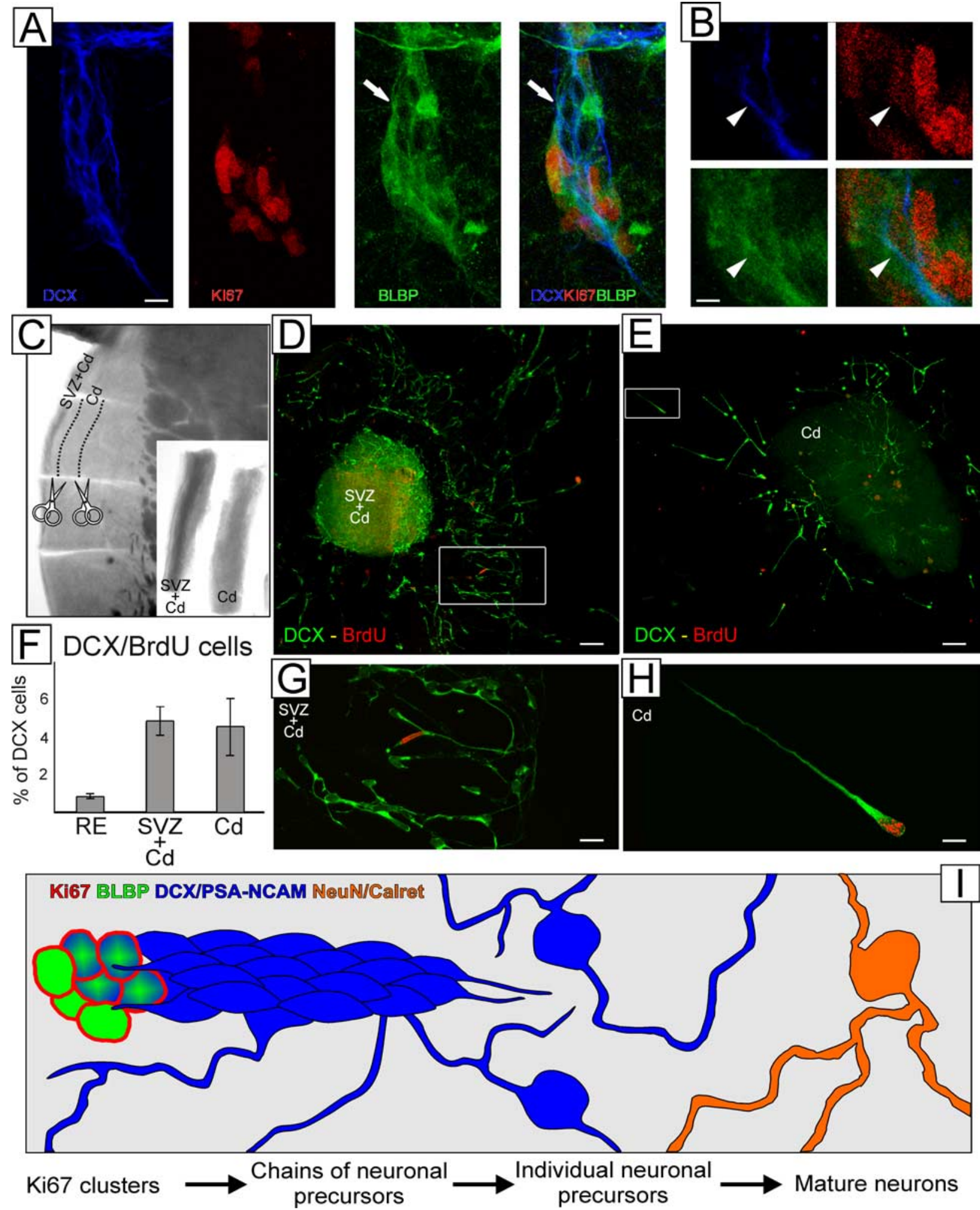

Figure 7. $\quad \boldsymbol{A}, \boldsymbol{B}$, Proliferating clusters of the caudate nucleus contain triple-labeled Ki67 (red)/DCX (blue)/BLBP (green)-positive cells. Most of the proliferating Ki67-positive cells are BLBP positive, whereas only a few express DCX. Note that a slight BLBP reaction, confined to the cytoplasm but not the nucleus (arrows), is apparent in Ki67-negative cells of the DCX-positive chain. $B$, A single confocal plane of $\boldsymbol{A}$ showing a triple-labeled cell (arrowheads). $\mathbf{C}-\boldsymbol{H}$, In vitro tissue explants. $\boldsymbol{C}$, A vibratome coronal section (300 $\mu \mathrm{m}$ thick) from which two stripes of tissue (inset) containing the SVZ $(\mathrm{SVZ}+\mathrm{Cd}$ ) and the caudate nucleus parenchyma (Cd) were dissected out. The SVZ appears as a darker thick line of tissue. Dorsal is up, and medial is right. After 4 div, DCX (green)-positive neuroblasts migrated out from both SVZ $+C d(\boldsymbol{D}, \boldsymbol{G})$ and $\mathrm{Cd}(\boldsymbol{E}, \boldsymbol{H})$ explants. Some of them contain BrdU (red), which was injected $3 \mathrm{~h}$ before the animals were killed. Note that, although many neuroblasts, often organized as chains, surround the SVZ+Cd explant, only a small number of individual elements have migrated out from the Cd explant. $F$, Percentage of BrdU/DCX neuroblasts migrated out of the $\mathrm{Cd}, \mathrm{SVZ}+\mathrm{Cd}$, and RE explants. This value is significantly lower in RE compared with both SVZ + Cd and Cd (Cd vs RE, $p=0.009 ; \mathrm{SVZ}+\mathrm{Cd}$ vs RE, $p=0.006 ; \mathrm{SVZ}+\mathrm{CdVs}$ Cd, $p=0.923) . I$, Neurogenesis in the caudate nucleus of adult rabbit (schematic representation). Four major steps can be hypothesized. Chains of neuronal precursors (step 2) are produced from Ki67 clusters that express both glial and neuronal antigens (step 1). Individual neuronal precursors leave the chains (step 3) and ultimately differentiate into mature neurons (step 4). Scale bars: $\boldsymbol{A}, 7.5 \mu \mathrm{m} ; \boldsymbol{B}, 3.75 \mu \mathrm{m} ; \boldsymbol{D}, \boldsymbol{E}, 50 \mu \mathrm{m}$; $\mathbf{G}, 20 \mu \mathrm{m} ; \boldsymbol{H}, 10 \mu \mathrm{m}$ 
cells located in the caudate nucleus. Phenotypic analysis of the newly formed neurons showed that at least one part of these cells differentiates into calretinin-positive striatal interneurons.

\section{Newly generated neurons}

After BrdU injections, a certain degree of proliferative activity was found in the striatum of adult rabbit. As described in other studies in the adult mammalian CNS, this proliferation is mainly associated to the genesis of long-lasting non-neuronal cells (Ehninger and Kempermann, 2003; Dayer et al., 2005). Our data indicate that, within the caudate nucleus, after 2 months, only $\sim 0.7 \%$ of the survived BrdU cells corresponds to NeuN neogenerated neurons.

More than $90 \%$ of striatal neurons are spiny projection neurons. Four major classes of other neuronal types constitute the striatal interneurons (Kawaguchi et al., 1995). Here, we demonstrated that, after $65 \mathrm{~d}$ from BrdU treatment, a subpopulation of newly generated NeuN-positive neurons expresses calretinin (Table 1). In the striatum, calretinin is expressed by one small subclass of GABAergic interneurons (Kubota et al., 1993). The mature morphological features shown by the newly generated calretinin neurons in the long-term survivors indicate that they represent the result of a process of genesis and differentiation. Indeed, we never found any double BrdU/calretinin and BrdU/ NeuN-positive elements in animals analyzed $5 \mathrm{~d}$ after daily injections of BrdU, thus excluding that our data have been misled by the presence of ectopic SVZ calretinin-positive neuroblasts (Jankovski and Sotelo, 1996) and/or by incorporation of BrdU in DNA repair mechanisms.

Our data indicate that, as in the other adult neurogenic systems, the newly generated neurons of the striatum originate from a population of neuronal precursors characterized by transient expression of early neuronal markers such as PSA-NCAM, DCX, class III $\beta$-tubulin, and $\mathrm{HuC/D}$ protein. Similar to the SVZ-OB system (Peretto et al., 1999), neuronal precursors are initially organized as chains. A developmental progression of this population has been described in this study, through a detailed stereological analysis of newly formed cells. A progressive loss of elements from the chains parallels an increase in the number of individual neuronal precursors. The latter cells very likely represent immature forms of the newly generated NeuN-positive neurons because (1) they precede their appearance, (2) they have comparable number, and (3) they show features and express markers of differentiating neurons. Notably, the individual neuronal precursors and the newly formed mature neurons represent only a small percentage of the neuronal precursor population. Indeed, at $65 \mathrm{~d}$, the NeuN/BrdU neurons correspond to $<10 \%$ of the mean number of the DCX/BrdU cells found at $5 \mathrm{~d}$ survival time, indicating the occurrence of a strong selection. Comparison with the SVZ and hippocampus, in which $\sim 50 \%$ of the neuronal precursors became mature neurons (Petreanu and AlvarezBuylla, 2002; Kempermann et al., 2004b), indicates that neuroblast survival within the adult caudate nucleus is very low. Strong selection and poor integration of new neurons within the striatum has also been described after lesion-induced neurogenesis (Arvidsson et al., 2002; Collin et al., 2005). Thus, adult striatum represents an unfavorable environment for the survival rather than genesis of the newly formed neurons. This observation raises questions about the relevance of neurogenesis in this area and might suggest a putative, not yet described, function of the immature neuronal precursors. At the same time, whereas the density of newly generated calretinin cells we found was very low (Table 1), the striatal calretinin interneurons represent a dis- persed cell population corresponding only to nearly $0.5 \%$ of the striatal neurons (Kawaguchi et al., 1995; Rymar et al., 2004). Therefore, if we refer to the striatal calretinin population, the percentage of newly generated calretinin cells, obtained after five BrdU injections, corresponds to $\sim 0.1 \%$, and thus striatal neurogenesis could play a role in the regulation of the number of these interneurons.

Our phenotypic analysis showed that most of the newly formed NeuN neurons did not express any of the major striatal markers. This result opens unresolved questions and possible hypotheses. First, it is possible that a subpopulation of newly generated neurons bears classes of not yet described neurons (Kawaguchi et al., 1995). Moreover, we cannot exclude that processes of selection and/or integration within the mature striatal tissue could be longer than in the $\mathrm{OB}$ and hippocampus. In agreement with this possibility, animals that survived $35 \mathrm{~d}$ after BrdU treatment showed the highest level of individual newly generated PSA-NCAM/DCX-positive neuroblasts, when, at comparable survival times, in both $\mathrm{OB}$ and hippocampus of rodents, the newly generated cells are fully differentiated and the expression of these markers is downregulated (Petreanu and Alvarez-Buylla, 2002; Brown et al., 2003; Kempermann et al., 2004b).

\section{Parenchymal progenitors}

Numerous studies have demonstrated that the adult SVZ of rodents can direct, after specific stimuli such as lesions (Arvidsson et al., 2002; Parent et al., 2002) and/or infusion of growth factors (Pencea et al., 2001; Jin et al., 2003; Chmielnicki et al., 2004), a large number of neuroblasts to the striatum. Moreover, comparative studies performed on primates (Gould et al., 1999, 2001; Bedard et al., 2002; Bernier et al., 2002) and on rabbits (Luzzati et al., 2003) further indicate the SVZ as the source of neuroblasts not exclusively directed to the OB. The identification of neurogenesis in the caudate nucleus and the existence of a system of chains of neuroblasts described in this study are thus apparently consistent with an SVZ dispenser mechanism. Nevertheless, our analyses suggest that striatal neurogenic activity in adult rabbit is, at least in part, independent from the adjacent SVZ neurogenesis. First, we demonstrated that striatal chains are closely correlated with local Ki67 proliferating cells. These cells are organized in small clusters that form specialized proliferating regions of the chains. These proliferating clusters can thus represent the site of origin of the striatal chains. Moreover, 3D reconstructions and CTG stereotaxic injections showed that striatal chains are completely separated from the SVZ. Therefore, although we cannot exclude that a few SVZ neuroblasts may migrate into the striatum, our data strongly suggest that the genesis of striatal chains, and therefore addition of new neurons in the caudate nucleus, is mostly attributable to the activity of local progenitors rather than proliferative activity of the SVZ. This hypothesis is also supported by our in vitro study. Indeed, isolated striatal explants, in which the dividing progenitors were labeled in vivo with a BrdU pulse $3 \mathrm{~h}$ before they were killed, generated BrdU-positive migrating neuroblasts. This result gives direct evidence of the existence of neuronal progenitors within the striatal parenchyma. Interestingly, we found a comparable percentage of DCX migrating neuroblasts that were BrdU positive in both striatal and SVZ explants, indicating the existence of a considerable proliferative activity of the adult caudate nucleus neuronal progenitors.

Technical approaches used and developmental stages analyzed cannot lead to deeper considerations on the origin and potentiality of the striatal proliferating progenitors. Nevertheless, clusters of highly proliferating cells have been identified in both 
SVZ and hippocampus (Doetsch et al., 1997, 1999; Kempermann et al., 2004b; Seri et al., 2004). These elements act as transit amplifying cells characterized by an intense proliferative activity. We can thus hypothesize that the proliferating Ki67 clusters identified in the caudate nucleus can represent a population of transit amplifying cells able to generate chains of neuronal precursors that ultimately differentiate into neurons (Fig. 7I).

In vivo, phenotypic analyses indicated that $\sim 85 \%$ of the proliferating Ki67 cluster cells express the glial marker BLBP. This protein is abundant in the radial glia, which serve as neuronal progenitors in all regions of the CNS (Anthony et al., 2004) and give rise to adult neural stem cells of the SVZ (Merkle et al., 2004). Moreover, nearly $60 \%$ of proliferating elements of the same clusters also express the early neuronal marker DCX. Thus, as demonstrated by triple immunolabeling experiments, some of the proliferating cells are positive for both glial and neuronal markers, suggesting a clonal relationship between BLBP- and DCXexpressing cells. Interestingly, in rodent hippocampus, progressive stages of development of the transit amplifying cells include, as in our system, coexpression of both glial (nestin-green fluorescent protein) and early neuronal (DCX/PSA-NCAM) markers (Kempermann et al., 2004b; Seri et al., 2004). A similar model of local neurogenesis can be hypothesized in the caudate nucleus of adult rabbit.

We cannot exclude that local striatal neurogenesis in adult rabbit might represent a peculiar characteristic of this species. However, differences in the extent of the adult neurogenesis between mammalian species may allow the discovery of neurogenic regulative factors. Interestingly, in our study, we demonstrate a high interindividual variability in the number of neuronal precursors and their local progenitors, suggesting the existence of molecular factors able to differentially enhance or suppress neuronal precursors production. Knowledge of these factors can be a useful tool to delineate cell-replacement strategies to restore function in neurodegenerative disorders.

\section{References}

Alvarez-Buylla A, Seri B, Doetsch F (2002) Identification of neural stem cells in the adult vertebrate brain. Brain Res Bull 57:751-758.

Anderson KD, Reiner A (1991) Immunohistochemical localization of DARPP-32 in striatal projection neurons and striatal interneurons: implications for the localization of D1-like dopamine receptors on different types of striatal neurons. Brain Res 568:235-243.

Anthony TE, Klein C, Fishell G, Heintz N (2004) Radial glia serve as neuronal progenitors in all regions of the central nervous system. Neuron 41:881-890.

Arvidsson A, Collin T, Kirik D, Kokaia Z, Lindvall O (2002) Neuronal replacement from endogenous precursors in the adult brain after stroke. Nat Med 8:963-970.

Bedard A, Levesque M, Bernier PJ, Parent A (2002) The rostral migratory stream in adult squirrel monkeys: contribution of new neurons to the olfactory tubercle and involvement of the antiapoptotic protein Bcl-2. Eur J Neurosci 16:1917-1924.

Belluzzi O, Benedusi M, Ackman J, LoTurco JJ (2003) Electrophysiological differentiation of new neurons in the olfactory bulb. J Neurosci 23:10411-10418.

Benraiss A, Chmielnicki E, Lerner K, Roh D, Goldman SA (2001) Adenoviral brain-derived neurotrophic factor induces both neostriatal and olfactory neuronal recruitment from endogenous progenitor cells in the adult forebrain. J Neurosci 21:6718-6731.

Bernier PJ, Bedard A, Vinet J, Levesque M, Parent A (2002) Newly generated neurons in the amygdala and adjoining cortex of adult primates. Proc Natl Acad Sci USA 99:11464-11469.

Bonfanti L, Theodosis DT (1994) Expression of polysialylated neural cell adhesion molecule by proliferating cells in the subependymal layer of the adult rat, in its rostral extension and in the olfactory bulb. Neuroscience 62:291-305.
Bonfanti L, Olive S, Poulain DA, Theodosis DT (1992) Mapping of the distribution of polysialylated neural cell adhesion molecule throughout the central nervous system of the adult rat: an immunohistochemical study. Neuroscience 49:419-436.

Brown JP, Couillard-Despres S, Cooper-Kuhn CM, Winkler J, Aigner L, Kuhn HG (2003) Transient expression of doublecortin during adult neurogenesis. J Comp Neurol 467:1-10.

Carleton A, Petreanu LT, Lansford R, Alvarez-Buylla A, Lledo PM (2003) Becoming a new neuron in the adult olfactory bulb. Nat Neurosci 6:507-518.

Chmielnicki E, Benraiss A, Economides AN, Goldman SA (2004) Adenovirally expressed noggin and brain-derived neurotrophic factor cooperate to induce new medium spiny neurons from resident progenitor cells in the adult striatal ventricular zone. J Neurosci 24:2133-2142.

Collin T, Arvidsson A, Kokaia Z, Lindvall O (2005) Quantitative analysis of the generation of different striatal neuronal subtypes in the adult brain following excitotoxic injury. Exp Neurol 195:71-80.

Dayer AG, Cleaver KM, Abouantoun T, Cameron HA (2005) New GABAergic interneurons in the adult neocortex and striatum are generated from different precursors. J Cell Biol 168:415-427.

De Marchis S, Fasolo A, Shipley M, Puche A (2001) Unique neuronal tracers show migration and differentiation of SVZ progenitors in organotypic slices. J Neurobiol 49:326-338.

De Marchis S, Fasolo A, Puche A (2004) Subventricular zone-derived neuronal progenitors migrate into the subcortical forebrain of postnatal mice. J Comp Neurol 476:290-300.

Doetsch F, Alvarez-Buylla A (1996) Network of tangential pathways for neuronal migration in adult mammalian brain. Proc Natl Acad Sci USA 93:14895-14900.

Doetsch F, Garcia-Verdugo JM, Alvarez-Buylla A (1997) Cellular composition and three-dimensional organization of the subventricular germinal zone in the adult mammalian brain. J Neurosci 17:5046-5061.

Doetsch F, Garcia-Verdugo JM, Alvarez-Buylla A (1999) Regeneration of a germinal layer in the adult mammalian brain. Proc Natl Acad Sci USA 96:11619-11624.

Ehninger D, Kempermann G (2003) Regional effects of wheel running and environmental enrichment on cell genesis and microglia proliferation in the adult murine neocortex. Cereb Cortex 13:845-851.

Fallon J, Reid S, Kinyamu R, Opole I, Opole R, Baratta J, Korc M, Endo TL, Duong A, Nguyen G, Karkehabadhi M, Twardzik D, Patel S, Loughlin S (2000) In vivo induction of massive proliferation, directed migration, and differentiation of neural cells in the adult mammalian brain. Proc Natl Acad Sci USA 97:14686-14691.

Feng L, Hatten ME, Heintz N (1994) Brain lipid-binding protein (BLBP): a novel signaling system in the developing mammalian CNS. Neuron 12:895-908.

Goldman SA (1997) Comparative strategies of subependymal neurogenesis in the adult forebrain. In: Isolation, characterization and utilization of CNS stem cells (Gage, FH, Christen Y, eds), pp 43-65. Berlin: Springer.

Gould E, Reeves AJ, Graziano MS, Gross CG (1999) Neurogenesis in the neocortex of adult primates. Science 286:548-552.

Gould E, Vail N, Wagers M, Gross CG (2001) Adult-generated hippocampal and neocortical neurons in macaques have a transient existence. Proc Natl Acad Sci USA 98:10910-10917.

Gundersen HJ, Bagger P, Bendtsen TF, Evans SM, Korbo L, Marcussen N, Moller A, Nielsen K, Nyengaard JR, Pakkenberg B (1988) The new stereological tools: disector, fractionator, nucleator and point sampled intercepts and their use in pathological research and diagnosis. APMIS 96:857-881.

Hartfuss E, Galli R, Heins N, Gotz M (2001) Characterization of CNS precursor subtypes and radial glia. Dev Biol 229:15-30.

Jankovski A, Sotelo C (1996) Subventricular zone-olfactory bulb migratory pathway in the adult mouse: cellular composition and specificity as determined by heterochronic and heterotopic transplantation. J Comp Neurol 371:376-396.

Jin K, Sun Y, Xie L, Peel A, Mao XO, Batteur S, Greenberg DA (2003) Directed migration of neuronal precursors into the ischemic cerebral cortex and striatum. Mol Cell Neurosci 24:171-189.

Kawaguchi Y, Wilson CJ, Augood SJ, Emson PC (1995) Striatal interneurones: chemical, physiological and morphological characterization. Trends Neurosci 18:527-535.

Kempermann G, Kuhn HG, Gage FH (1997) Genetic influence on neuro- 
genesis in the dentate gyrus of adult mice. Proc Natl Acad Sci USA 94:10409-10414.

Kempermann G, Gast D, Kronenberg G, Yamaguchi M, Gage FH (2003) Early determination and long-term persistence of adult-generated new neurons in the hippocampus of mice. Development 130:391-399.

Kempermann G, Wiskott L, Gage FH (2004a) Functional significance of adult neurogenesis. Curr Opin Neurobiol 14:186-191.

Kempermann G, Jessberger S, Steiner B, Kronenberg G (2004b) Milestones of neuronal development in the adult hippocampus. Trends Neurosci 27:447-452.

Kirschenbaum B, Nedergaard M, Preuss A, Barami K, Fraser RA, Goldman SA (1994) In vitro neuronal production and differentiation by precursor cells derived from the adult human forebrain. Cereb Cortex 4:576-589.

Kondo T, Raff M (2000) Oligodendrocyte precursor cells reprogrammed to become multipotential CNS stem cells. Science 289:1754-1757.

Kronenberg G, Reuter K, Steiner B, Brandt MD, Jessberger S, Yamaguchi M, Kempermann G (2003) Subpopulations of proliferating cells of the adult hippocampus respond differently to physiologic neurogenic stimuli. J Comp Neurol 467:455-463.

Kubota Y, Mikawa S, Kawaguchi Y (1993) Neostriatal GABAergic interneurones contain NOS, calretinin or parvalbumin. NeuroReport 5:205-208.

Kurtz A, Zimmer A, Schnutgen F, Bruning G, Spener F, Muller T (1994) The expression pattern of a novel gene encoding brain-fatty acid binding protein correlates with neuronal and glial cell development. Development 120:2637-2649.

Luzzati F, Peretto P, Aimar P, Ponti G, Fasolo A, Bonfanti L (2003) Gliaindependent chains of neuroblasts through the subcortical parenchyma of the adult rabbit brain. Proc Natl Acad Sci USA 100:13036-13041.

Magavi SS, Leavitt BR, Macklis JD (2000) Induction of neurogenesis in the neocortex of adult mice. Nature 405:951-955.

Menezes JR, Luskin MB (1994) Expression of neuron-specific tubulin defines a novel population in the proliferative layers of the developing telencephalon. J Neurosci 14:5399-5416.

Merkle FT, Tramontin AD, Garcia-Verdugo JM, Alvarez-Buylla A (2004) Radial glia give rise to adult neural stem cells in the subventricular zone. Proc Natl Acad Sci USA 101:17528-17532.

Mullen RJ, Buck CR, Smith AM (1992) NeuN, a neuronal specific nuclear protein in vertebrates. Development 116:201-211.

Nacher J, Crespo C, McEwen BS (2001) Doublecortin expression in the adult rat telencephalon. Eur J Neurosci 14:629-644.

Palmer TD, Markakis EA, Willhoite AR, Safar F, Gage FH (1999) Fibroblast growth factor- 2 activates a latent neurogenic program in neural stem cells from diverse regions of the adult CNS. J Neurosci 19:8487-8497.

Parent JM, Vexler ZS, Gong C, Derugin N, Ferriero DM (2002) Rat fore- brain neurogenesis and striatal neuron replacement after focal stroke. Ann Neurol 52:802-813.

Pencea V, Bingaman KD, Wiegand SJ, Luskin MB (2001) Infusion of brainderived neurotrophic factor into the lateral ventricle of the adult rat leads to new neurons in the parenchyma of the striatum, septum, thalamus, and hypothalamus. J Neurosci 21:6706-6717.

Peretto P, Merighi A, Fasolo A, Bonfanti L (1999) The subependymal layer in rodents: a site of structural plasticity and cell migration in the adult mammalian brain. Brain Res Bull 49:221-243.

Petreanu L, Alvarez-Buylla A (2002) Maturation and death of adult-born olfactory bulb granule neurons: role of olfaction. J Neurosci 22:6106-6113.

Rakic P (2004) Neuroscience: immigration denied. Nature 427:685-686.

Reynolds BA, Weiss S (1992) Generation of neurons and astrocytes from isolated cells of the adult mammalian central nervous system. Science 255:1707-1710

Rochefort C, Gheusi G, Vincent JD, Lledo PM (2002) Enriched odor exposure increases the number of newborn neurons in the adult olfactory bulb and improves odor memory. J Neurosci 22:2679-2689.

Romfh JH (1976) Anatomical and experimental study of certain association fascicles in the cortex of the rabbit (Oryctalagus cuniculus). J Hirnforsch 17:539-558.

Rymar VV, Sasseville R, Luk KC, Sadikot AF (2004) Neurogenesis and stereological morphometry of calretinin-immunoreactive GABAergic interneurons of the neostriatum. J Comp Neurol 469:325-339.

Sanai N, Tramontin AD, Quinones-Hinojosa A, Barbaro NM, Gupta N, Kunwar S, Lawton MT, McDermott MW, Parsa AT, Manuel-Garcia Verdugo J, Berger MS, Alvarez-Buylla A (2004) Unique astrocyte ribbon in adult human brain contains neural stem cells but lacks chain migration. Nature 427:740-744.

Scholzen T, Gerdes J (2000) The Ki-67 protein: from the known and the unknown. J Cell Physiol 182:311-322.

Seri B, Garcia-Verdugo JM, Collado-Morente L, McEwen BS, Alvarez-Buylla A (2004) Cell types, lineage, and architecture of the germinal zone in the adult dentate gyrus. J Comp Neurol 478:359-378.

van Praag H, Schinder AF, Christie BR, Toni N, Palmer TD, Gage FH (2002) Functional neurogenesis in the adult hippocampus. Nature 415:1030-1034.

Weiss S, Dunne C, Hewson J, Wohl C, Wheatley M, Peterson AC, Reynolds BA (1996) Multipotent CNS stem cells are present in the adult mammalian spinal cord and ventricular neuroaxis. J Neurosci 16:7599-7609.

Williams RW, Rakic P (1988) Three-dimensional counting: an accurate and direct method to estimate numbers of cells in sectioned material. J Comp Neurol 278:344-352. 